\title{
Synaptic Targeting of N-Type Calcium Channels in Hippocampal Neurons
}

\author{
Anton Maximov and llya Bezprozvanny \\ Department of Physiology, University of Texas Southwestern Medical Center at Dallas, Dallas, Texas 75390
}

$\mathrm{N}$-type calcium $\left(\mathrm{Ca}^{2+}\right)$ channels play a critical role in synaptic function, but the mechanisms responsible for their targeting in neurons are poorly understood. N-type channels are formed by an $\alpha_{1 \mathrm{~B}}\left(\mathrm{Ca}_{\mathrm{V}} 2.2\right)$ pore-forming subunit associated with $\beta$ and $\alpha 2 \delta$ auxiliary subunits. By expressing epitope-tagged recombinant $\alpha_{1 \mathrm{~B}}$ subunits in rat hippocampal neuronal cultures, we demonstrate here that synaptic targeting of $\mathrm{N}$-type channels depends on neuronal contacts and synapse formation. We also establish that the C-terminal 163 aa (2177-2339) of the $\alpha_{1 \mathrm{~B}-1}$ $\left(\mathrm{Ca}_{\mathrm{v}} 2.2 \mathrm{a}\right)$ splice variant contain sequences that are both necessary and sufficient for synaptic targeting. By site-directed mutagenesis, we demonstrate that postsynaptic density-95/ discs large/zona occludens-1 and Src homology 3 domainbinding motifs located within this region of the $\alpha_{1 \mathrm{~B}}$ subunit (Maximov et al., 1999) act as synergistic synaptic targeting signals. We also show that the recombinant modular adaptor proteins Mint1 and CASK colocalize with $\mathrm{N}$-type channels in synapses. We found that the $\alpha_{1 \mathrm{~B}-2}\left(\mathrm{Ca}_{\mathrm{v}} 2.2 \mathrm{~b}\right)$ splice variant is restricted to soma and dendrites and postulated that somatodendritic and axonal/presynaptic isoforms of $\mathrm{N}$-type channels are generated via alternative splicing of $\alpha_{1 \mathrm{~B}} \mathrm{C}$ termini. These data lead us to propose that during synaptogenesis, the $\alpha_{1 \mathrm{~B}-1}$ $\left(\mathrm{Ca}_{\mathrm{v}} 2.2 \mathrm{a}\right)$ splice variant of the $\mathrm{N}$-type $\mathrm{Ca}^{2+}$ channel poreforming subunit is recruited to presynaptic locations by means of interactions with modular adaptor proteins Mint1 and CASK. Our results provide a novel insight into the molecular mechanisms responsible for targeting of $\mathrm{Ca}^{2+}$ channels and other synaptic proteins in neurons.

Key words: calcium channels; polarized cells; PDZ domains; protein targeting; axons; synapse
Neurons are highly polarized cells: the structural, functional, and molecular differences between their axonal and somatodendritic domains underlie their ability to receive, process, and transmit information. The unique complement of ion channels, receptors, and cytoplasmic and cytoskeleton proteins is present in neuronal somatodendritic and axonal compartments (Craig and Banker, 1994). Cellular and molecular mechanisms involved in targeting of neuronal proteins have been elucidated recently (Higgins et al., 1997; Winckler and Mellman, 1999). Primary cultures of rat hippocampal neurons are the most widely used model for these studies. Axons and dendrites of hippocampal neurons display distinctive and characteristic morphologies; axons are consistently presynaptic, and dendrites are consistently postsynaptic (Craig and Banker, 1994). Correct localization of synaptic constituents in hippocampal neurons has been proposed to result from a two-step process: initial targeting to axonal or somatodendritic domains based on intrinsic sorting signals, followed by clustering at presynaptic and postsynaptic sites that depends on cell-to-cell contacts (Craig and Banker, 1994).

Presynaptic voltage-gated $\mathrm{Ca}^{2+}$ channels mediate rapid $\mathrm{Ca}^{2+}$

Received Feb. 21, 2002; revised May 17, 2002; accepted May 21, 2002.

This work was supported by the Robert A. Welch Foundation and by National Institutes of Health Grant R01 NS39552 (I.B.). We are grateful to Ege Kavalali, Marcus Missler, Thomas Biederer, Gary Banker, and Thomas C. Südhof for helpful discussions, experimental advice, and comments on this manuscript, and to Nan Wang and Phyllis Foley for expert technical and administrative assistance. We thank R. W. Tsien for N-type $\mathrm{Ca}^{2+}$ channel clones, Thomas C. Südhof for Mint1, CASK, and pCMV-HA plasmids and synapsin and PSD-95 antibodies, Boris Shtonda for the CD4-NC construct, Koki Moriyoshi and Ann Marie Craig for mGFP construct, Nikolay Shcheynikov for the help with oocyte expression, and Elena Nosyreva for assistance with experiments.

Correspondence should be addressed to Dr. Ilya Bezprozvanny, Department of Physiology, University of Texas Southwestern Medical Center at Dallas, Dallas, TX 75390-9040. E-mail: Ilya.Bezprozvanny@UTSouthwestern.edu.

Copyright $(\odot 2002$ Society for Neuroscience $0270-6474 / 02 / 226939-14 \$ 15.00 / 0$ influx into the synaptic terminal that triggers synaptic vesicle exocytosis and neurotransmitter release (Llinas et al., 1981). Multiple types of $\mathrm{Ca}^{2+}$ channels (N-type, P/Q-type, L-type, R-type, and T-type) are expressed in neurons (Tsien et al., 1991). $\mathrm{N}$-type $\mathrm{Ca}^{2+}$ channels [encoded by the $\alpha_{1 \mathrm{~B}}\left(\mathrm{Ca}_{\mathrm{V}} 2.2\right)$ poreforming subunit] (Williams et al., 1992; Ertel et al., 2000) and $\mathrm{P} / \mathrm{Q}$-type $\mathrm{Ca}^{2+}$ channels [encoded by the $\alpha_{1 \mathrm{~A}}\left(\mathrm{Ca}_{\mathrm{V}} 2.1\right)$ poreforming subunit] (Mori et al., 1991; Ertel et al., 2000) play a predominant role in supporting chemical neurotransmission in central synapses (Takahashi and Momiyama, 1993; Wheeler et al., 1994; Dunlap et al., 1995; Reuter, 1995). How are N-type and $\mathrm{P} / \mathrm{Q}$-type $\mathrm{Ca}^{2+}$ channels targeted to synaptic locations? It has been demonstrated that neuron-to-neuron contact is required for $\mathrm{N}$-type $\mathrm{Ca}^{2+}$ channel clustering during synapse formation in rat hippocampal neuronal culture (Bahls et al., 1998). More recently, synaptic targeting of an auxiliary $\mathrm{P} / \mathrm{Q}$-type $\mathrm{Ca}^{2+}$ channel subunit $\beta_{4}$ was investigated (Wittemann et al., 2000). However, a number of fundamental questions regarding synaptic $\mathrm{Ca}^{2+}$ channel targeting to the synapse remain unanswered.

Here we investigated targeting of recombinant $\mathrm{N}$-type $\mathrm{Ca}^{2+}$ channels to synaptic locations in rat hippocampal neuronal cultures. We found that in immature and in mature low-density hippocampal cultures, recombinant $\mathrm{N}$-type $\mathrm{Ca}^{2+}$ channels were uniformly distributed in both axonal and somatodendritic compartments. In contrast, in mature high-density cultures, the recombinant $\mathrm{N}$-type $\mathrm{Ca}^{2+}$ channels were clustered in presynaptic sites and primarily excluded from the somatodendritic domain. Synaptic clustering of recombinant N-type channels depended critically on the most C-terminal region of the "long" splice variant of the $\mathrm{N}$-type $\mathrm{Ca}^{2+}$ channel pore-forming subunit $\alpha_{1 \mathrm{~B}-1}$ $\left(\mathrm{Ca}_{\mathrm{V}} 2.2 \mathrm{a}\right)$ (Williams et al., 1992; Ertel et al., 2000). In a previous paper, we identified postsynaptic density-95 (PSD-95)/discs large/ 
zona occludens-1 (PDZ) and Src homology 3 (SH3) domainbinding motifs in the same region of the $\alpha_{1 \mathrm{~B}}$ subunit (Maximov et al., 1999). Here we show that these motifs act as synergistic synaptic targeting signals for $\mathrm{N}$-type channels in rat hippocampal neurons. Our results provide a novel insight into the molecular mechanisms responsible for targeting of $\mathrm{Ca}^{2+}$ channels and other synaptic proteins in neurons.

\section{MATERIALS AND METHODS}

Expression constructs. The human $\alpha_{1 \mathrm{~B}}$ (Ellinor et al., 1994), rabbit $\alpha_{2} / \delta-1$ (Mikami et al., 1989), and rabbit $\beta_{3}$ (Hullin et al., 1992) coding sequences were subcloned into mammalian expression vectors [pCMV-HA (a gift from Thomas Südhof, University of Texas Southwestern Medical Center, Dallas, TX) or pcDNA3 (Invitrogen, San Diego, CA)]. The following expression constructs were generated: hemagglutinin $(\mathrm{HA})-\alpha_{1 \mathrm{~B}}=$ 1-2339 [the HA tag is connected to the $\alpha_{1 \mathrm{~B}}$ sequence via GIPQRNPEPLALCR linker; the first 72 aa in the $\alpha_{1 \mathrm{~B}}$ sequence are replaced by the homologous sequence from $\alpha_{1 \mathrm{~A}}$ as explained by Ellinor et al. (1994)], $\alpha_{1 \mathrm{~B}}$-II/III-HA $=1-2339$ (the HA tag was introduced between positions $\mathrm{G}^{844}$ and $\mathrm{V}^{845}$ of the $\alpha_{1 \mathrm{~B}}$ sequence), HA- $\alpha_{1 \mathrm{~B}}$-T2038X $=1-2038$, HA$\alpha_{1 \mathrm{~B}} \mathrm{~S} 2176 \mathrm{X}=1-2176, \mathrm{HA}-\alpha_{1 \mathrm{~B}}-\mathrm{D} 2334 \mathrm{X}=1-2333$, HA- $\alpha_{1 \mathrm{~B}}-\mathrm{PXXP}-\mathrm{A}=$ $1-2339 \quad\left[\left({ }^{2191}\right.\right.$ PQTPLTPRP $\left.{ }^{2199}-(\mathrm{A})_{9}\right], \quad \mathrm{HA}-\alpha_{1 \mathrm{~B}} \mathrm{PXXP}-\mathrm{A} / \mathrm{D} 2334 \mathrm{X}=$ $1-2333\left[{ }^{2191}\right.$ PQTPLTPRP $\left.{ }^{2199}-(\mathrm{A})_{9}\right]$, and HA-NC3 $=2021-2339$. The HA- $\alpha_{1 \mathrm{~B}}$-rat NC2 splice variant (rNC2) construct was generated by replacing 2164-2339 aa of human HA- $\alpha_{1 \mathrm{~B}}$ construct with 2159-2299 aa of cloned rat NC2 splice variant (see below). All $\alpha_{1 \mathrm{~B}} \mathrm{C}$-terminal mutant and chimeric constructs were generated by cassette mutagenesis of human $\alpha_{1 \mathrm{~B}}$ coding sequence between XhoI (5304) and XbaI sites ( $3^{\prime}$ untranslated region). Wild-type coding sequence was replaced by mutated cassettes generated by standard or megaprimer PCR and subcloned into $X h o \mathrm{I} / X b a \mathrm{I}$ sites. The locus of mutations was verified by sequencing. CD4-NC targeting constructs were generated on the basis of pMACS4.1 (CD4) plasmid (Miltenyi Biotech, Sunnyvale, CA): CD4-NC $=1743-$ 2339 (1773-2275 and deletion 2306-2334), CD4-NC-D2334X $=2202-$ 2333; CD4-QC $=2376-2505$ of human $\alpha_{1 \mathrm{~A}}$ (Zhuchenko et al., 1997), and CD4-QC-D2501X $=2376-2501$ of human $\alpha_{1 \mathrm{~A}}$. Green fluorescent protein (GFP) fusion constructs were generated on the basis of pEGFPC3 (Clontech, Palo Alto, CA) vector: GFP-NC3 = 2021-2339, GFP-Mint1 = 1-839 of rat Mint1 (Okamoto and Sudhof, 1997), GFP-CASK = 1-909 of rat CASK (Hata et al., 1996). Before neuronal transfections, the generated HA- $\alpha_{1 \mathrm{~B}}$ and CD4 expression constructs were expressed in human embryonic kidney 293 (HEK293) or COS7 cells and analyzed by Western blotting with anti-HA (HA- $\left.\alpha_{1 \mathrm{~B}}\right)$ and anti-CD4 (CD4-NC) antibodies. All constructs were expressed in COS7 and HEK293 cells at similar levels, and their apparent molecular weights on the Western blot were in agreement with their predicted molecular weights (data not shown). In addition, we tested whether the wild-type and mutated HA- $\alpha_{1 \mathrm{~B}}$ targeting constructs support functional $\mathrm{Ca}^{2+}$ currents when expressed in Xenopus oocytes, as described previously (Bezprozvanny et al., 1995). The size of the peak current and the inactivation properties of the expressed wild-type and mutant channels measured $3 \mathrm{~d}$ after cRNA injection (quantified as ratio of the peak current to the current at the end of the $50 \mathrm{msec}$ pulse test pulse from $-100 \mathrm{mV}$ to $0 \mathrm{mV}$ ) are presented in Table 1.

Hippocampal neuronal cultures and neuronal transfection. Hippocampi were isolated from embryonic day 18 rat embryos and dissociated by digestion with trypsin (Invitrogen) and DNase I (Sigma, St. Louis, MO) (Goslin et al., 1998). Neurons were plated on glass coverslips coated with

Table 1. Functional properties of channels supported by the wild-type and mutant $\mathrm{HA}-\alpha_{1 \mathrm{~B}} / \alpha_{2} \delta / \beta_{3}$ subunit combinations expressed in Xenopus oocytes

\begin{tabular}{lcl} 
HA- $\alpha_{1 \mathrm{~B}}$ & Peak current $(\mu \mathrm{A})$ & $\begin{array}{l}\text { Peak current/end } \\
\text { of } 50 \mathrm{msec} \text { pulse }\end{array}$ \\
\hline HA- $\alpha_{1 \mathrm{~B}}-\mathrm{WT}$ & $0.8 \pm 0.4$ & $2.8 \pm 0.49$ \\
HA- $\alpha_{1 \mathrm{~B}}-\mathrm{D} 2334 \mathrm{X}$ & $0.59 \pm 0.09$ & $2.0 \pm 0.18$ \\
HA- $\alpha_{1 \mathrm{~B}}-\mathrm{S} 2176 \mathrm{X}$ & $0.39 \pm 0.04$ & $2.8 \pm 0.67$ \\
HA- $\alpha_{1 \mathrm{~B}}$-PXXP-A/D2334X & $0.45 \pm 0.06$ & $3.0 \pm 0.66$ \\
HA- $\alpha_{1 \mathrm{~B}}$-rNC2 & $0.67 \pm 0.1$ & $2.1 \pm 0.34$ \\
\hline
\end{tabular}

$n \geq 5$ for each group. WT, Wild type.
poly-L-lysine (Sigma) and cultured on glial cell monolayer in MEM (phenol red-free) supplemented with glucose, B-27 (Invitrogen), and sodium pyruvate. The neurons were plated at high $\left(60-80\right.$ neurons $\left./ \mathrm{mm}^{2}\right)$ or low (5-10 neurons $/ \mathrm{mm}^{2}$ ) density as indicated in Results. Glial cell growth was inhibited by $4 \mu \mathrm{M}$ AraC (Sigma). For transfection, conditioned medium was removed from cultures, and neurons were washed once in MEM and incubated for $30 \mathrm{~min}$ with the calcium-phosphateDNA precipitates formed in HEPES-buffered saline (Crawley et al., 1997). Cells were then returned into conditioned medium and analyzed 2-4 d after transfection. A mixture of $\mathrm{HA}-\alpha_{1 \mathrm{~B}} / \alpha_{2} \delta / \beta_{3}$ plasmids (molar ratio $3: 1: 1$ ) was used to express $\mathrm{N}$-type $\mathrm{Ca}^{2+}$ channels. The $\beta_{3}$ subunit expressed as an HA- or GFP-fusion protein was uniformly distributed in neurons cultured in vitro for 7-14 d (data not shown), which rules out the possibility that $\beta_{3}$ acts as an $\mathrm{N}$-type $\mathrm{Ca}^{2+}$ channel targeting subunit.

Antibodies. The following monoclonal antibodies were used (listed by antibody and working concentration): MAP2 (Sigma) 1:1000; synaptotagmin I (STI) (Synaptic Systems, Göttingen, Germany) 1:50; CD4 (Zymed, San Francisco, CA) 1:1000; CD4-FITC (Zymed) 1:100; HA.11 (Covance, Richmond, CA) 1:500; and synapsin I (Chemicon, Temecula, CA) 1:1000. Polyclonal MAP2 antibodies (Chemicon) were used at concentration of 1:500. When compared with monoclonal MAP2 antibodies, labeling with polyclonal MAP2 antibodies resulted in a more discrete pattern of distribution of marker in dendrites. In additional control experiments, we confirmed that the discrete staining pattern observed with polyclonal MAP2 antibodies does not result from fragmentation of neuronal processes. Polyclonal pan-synapsin and PSD-95 antibodies were kindly provided by Dr. Thomas Südhof and used at 1:1000. rNN antibodies have been described previously (Maximov et al., 1999). N-type splice-variant-specific C-terminal antibodies (NC1) were generated against a glutathione $S$-transferase fusion protein encoding C-terminal amino acids 2166-2333 of rat $\alpha_{1 \mathrm{~B}}$. Antibodies were purified by affinity chromatography and used at 1:200 for immunoblotting and at 1:50 for immunoprecipitation.

Immunocytochemistry. Neurons were washed once in PBS, fixed for $10-15$ min in $4 \%$ paraformaldehyde and $4 \%$ sucrose in PBS on ice, and permeabilized for $5 \mathrm{~min}$ at room temperature in $0.25 \%$ Triton X-100 in PBS. For labeling with STI antibodies, life neurons were washed once in PBS and incubated in modified tiroid solution containing (in $\mathrm{mM}$ ): 90 $\mathrm{NaCl}, 45 \mathrm{KCl}, 2 \mathrm{CaCl}_{2}, 1 \mathrm{MgCl}_{2}, 5$ HEPES, pH 7.2, and STI antibodies for $3 \mathrm{~min}$. Cells were then washed three times in PBS, fixed, and permeabilized. Nonspecific binding sites were blocked by incubation of cells for $30 \mathrm{~min}$ in 5\% BSA (fraction V; Sigma). Neurons were covered by primary antibodies diluted in blocking solution followed by incubation with the corresponding rhodamine- or FITC-conjugated secondary antibodies (Jackson ImmunoResearch, West Grove, PA). Slides were washed with PBS and mounted in Moweol-488 (Polysciences Inc., Warrington, PA). For the experiment shown on Figure $5 H$, life neurons were preincubated with $5 \mu \mathrm{M} \omega$-GVIA (Molecular Probes, Eugene, OR) or $\omega$-M V IIC (Amersham Pharmacia Biotech, Arlington Heights, IL) for 30 min before STI labeling. Images were collected with a Zeiss (Thornwood, NY) microscope with $40 \times$ and $63 \times$ objectives. Digital images were captured with a cooled CCD camera (PhotoMetrics, Huntington Beach CA) and Oncor (Gaithersburg, MD) Image software and analyzed using Adobe Photoshop (Adobe Systems, San Jose, CA) and Scion (Frederick, MD) Image software. The fluorescence intensity profiles shown for Figures 2, 3, and 6 were created by manual tracing of selected areas of axons. The confocal images shown for Figures $1 D, 2 G$, and $4 C$ were collected with a confocal Zeiss Axiovert 100 microscope and $63 \times$ objective. Neuronal cell bodies were scanned starting from the surface of the cell with a $0.2-\mu \mathrm{m}$-thickness parameter. Confocal images were collected in Z-stacks using laser-scanning microscope software (Zeiss).

Subcellular fractionation of brain. Subcellular brain fractions were isolated as described previously (Jones and Matus, 1974). Briefly, 12 rat brains were homogenized in $0.32 \mathrm{M}$ sucrose and $25 \mathrm{mM}$ HEPES, pH 7.2, and centrifuged for $10 \mathrm{~min}$ at $800 \times g$ to remove the nuclei. The low-speed supernatant was then centrifuged for $20 \mathrm{~min}$ at $12,000 \times g$ to separate synaptosomal supernatant and synaptosomal membrane fractions ( $\mathrm{P} 2$ pellet). $\mathrm{P} 2$ pellets were incubated for $30 \mathrm{~min}$ at $4^{\circ} \mathrm{C}$ in hypotonic

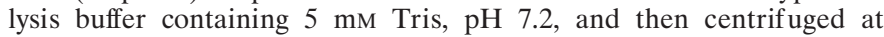
$25,000 \times g$ to separate synaptic vesicles and crude synaptosomal fractions (P3 pellet). P3 pellets were adjusted to $1.1 \mathrm{M}$ sucrose, loaded to the centrifuge tubes, and layered by solutions of 0.86 and $0.32 \mathrm{M}$ sucrose. Subcellular fractions were separated by centrifugation of samples for 2.5 hr at $48,000 \times g$. For Western blot analysis, equal amounts of protein were loaded to each lane. 


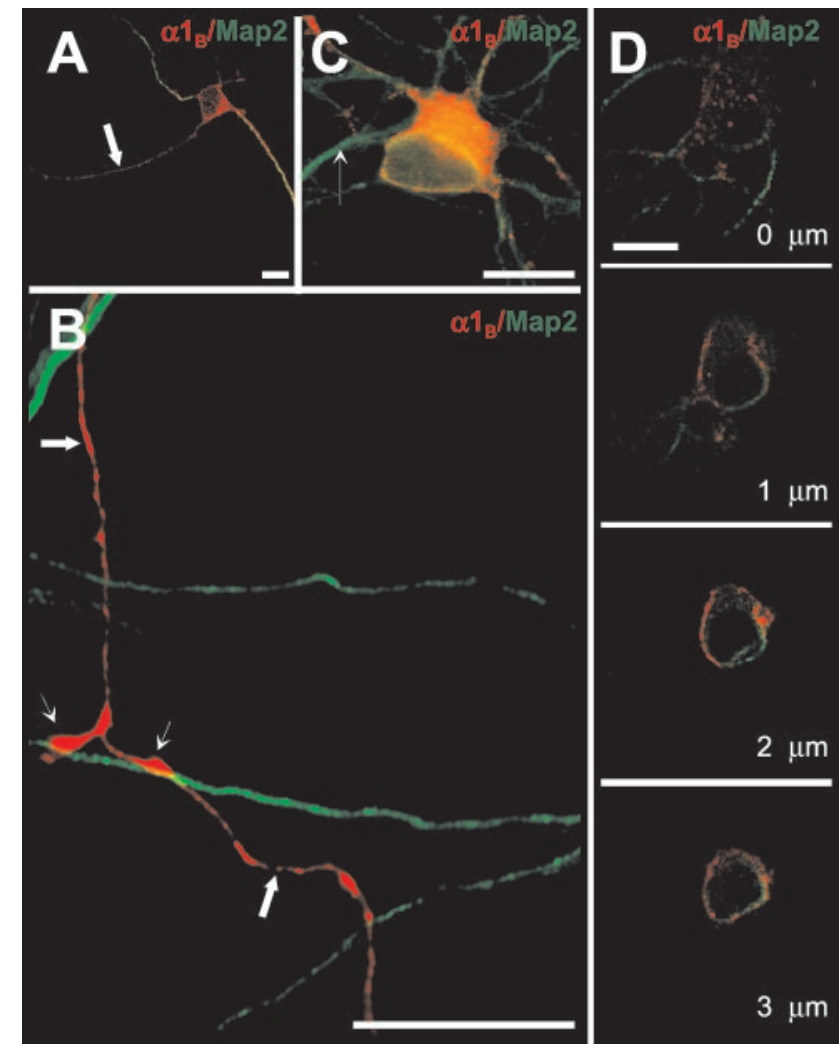

Figure 1. Distribution of recombinant N-type channels in immature hippocampal neurons. Hippocampal neurons cultured in high density were transfected with a mixture of HA- $\alpha_{1 \mathrm{~B}} / \alpha_{2} \delta / \beta_{3}$ cDNAs $2 \mathrm{~d}$ after plating. At $4 \mathrm{~d}$ after transfection, the neurons were fixed, permeabilized, and labeled with monoclonal anti-HA (red) and polyclonal anti-MAP2 (green) antibodies for conventional $(A-C)$ and confocal $(D)$ imaging. Scale bars, $20 \mu \mathrm{m}$. $A$, Recombinant HA- $\alpha_{1 \mathrm{~B}}$ is targeted to both axons (arrow, MAP2-negative) and dendrites (MAP2-positive processes) of immature neurons. $B$, Recombinant $\mathrm{HA}-\alpha_{1 \mathrm{~B}}$ is uniformly distributed in axons of transfected neurons (large arrows, MAP2-negative), with some degree of enrichment in zones of contacts between axons and dendrites of neighboring nontransfected cells (small arrows, MAP2-positive). $C$, Recombinant $\mathrm{HA}-\alpha_{1 \mathrm{~B}}$ is present in cell bodies and dendrites of transfected neurons. The dendrite of a neighboring untransfected cell is indicated by a small arrow. Only weak HA immunoreactivity was typically observed in the proximal axonal segment. $D$, Confocal analysis of recombinant HA$\alpha_{1 \mathrm{~B}}$ localization in the soma. Stacks of images were collected starting from the surface of the cell with $0.2 \mu \mathrm{m}$ thickness. Every fifth image from the stack is shown.

Immunoprecipitations. Samples of synaptosomal membranes, crude synaptosomes, and synaptic plasma membranes (SPMs) were solubilized in buffer containing 1\% 3-[(3-cholamidopropyl)dimethylammonio]-1propanesulfonate (CHAPS), 25 mM HEPES, pH 7.2, 10\% glycerol, 0.16 $\mathrm{M}$ sucrose, and protease inhibitors for $2 \mathrm{hr}$ at $4^{\circ} \mathrm{C}$. Insoluble material was removed by centrif ugation of samples for $20 \mathrm{~min}$ at $100,000 \times g$. Samples were prelabeled with $5 \mathrm{~nm}{ }^{125} \mathrm{I}-\omega$-GVIA (Amersham Pharmacia Biotech) for $1 \mathrm{hr}$ at $4^{\circ} \mathrm{C}$ and then incubated with protein A-Sepharose beads covered with $\mathrm{NN}$ or $\mathrm{NC1}$ antibodies or corresponding preimmune serum for $2 \mathrm{hr}$ at $4^{\circ} \mathrm{C}$. Beads were washed three times with the fivefold diluted solubilization buffer, and the number of ${ }^{125} \mathrm{I}-\omega$-GVIA binding sites precipitated by each antibody was measured with a gamma counter. Data were normalized to the total protein content in each fraction. Nonspecific binding measured with preimmune serum was subtracted from the data.

Cloning of $r N C 2$. Rat brain polyA RNA was isolated (STAT-60; Tel-Test, Inc., Friendswood, TX), and cDNA was generated from poly-dT primer with a RETROscript kit (Ambion, Austin, TX). Obtained cDNA was used as a template for nested PCR with two pairs of primers specific for rat $\alpha_{1 \mathrm{~B}}$ sequence (Q2294) FP1 = GCGCAGGGACAAGAAGCAGA, RP1 = CTAGCACCAGTGATCCTGGTCT; FP2 = CAGAGAAGCAGCGCT-
TCTATTCCT; RP2 = TCTGGGTGGTGGTAGCTGTG. The products of nested PCR were separated on agarose gel, purified, subcloned into pCR2.1 Topo plasmid (Invitrogen), and sequenced. The novel sequence of rNC2 splice variant was deposited into GenBank (accession number AF389419).

\section{RESULTS \\ Distribution of $\mathrm{N}$-type $\mathrm{Ca}^{2+}$ channels in immature rat hippocampal neurons}

To study $\mathrm{N}$-type $\mathrm{Ca}^{2+}$ channel targeting in neurons, we added $\mathrm{HA}$ tag to an $\mathrm{N}$ terminal of the long $\mathrm{C}$-terminal splice variant of the human N-type channel pore-forming subunit $\alpha_{1 \mathrm{~B}-1}\left(\mathrm{Ca}_{\mathrm{V}} 2.2 \mathrm{a}\right)$ (Williams et al., 1992; Ellinor et al., 1994; Ertel et al., 2000) and expressed the resulting HA- $\alpha_{1 \mathrm{~B}}$ construct in rat hippocampal neurons by $\mathrm{Ca}^{2+}$ phosphate-mediated transfection (see Materials and Methods). When expressed without auxiliary subunits, the HA- $\alpha_{1 \mathrm{~B}}$ construct was restricted to neuronal soma (data not shown), most likely because of retention in the endoplasmic reticulum (ER) (Bichet et al., 2000). Thus, in all experiments in this study the HA- $\alpha_{1 \mathrm{~B}}$ construct was coexpressed with the rabbit $\alpha_{2} \delta$-1 (Mikami et al., 1989) and rabbit $\beta_{3}$ (Hullin et al., 1992) subunits. We first analyzed distribution of recombinant N-type channels expressed in immature neurons [5-6 d in vitro (DIV)], before maturation of synaptic contacts and formation of a fully polarized phenotype. Both morphological criteria and MAP2 staining were used to discriminate between somatodendritic and axonal compartments of immature neurons in these experiments. The recombinant HA- $\alpha_{1 \mathrm{~B}}$ was detected in both somatodendritic and axonal domains of immature neurons (Fig. $1 A, C$ ). The recombinant N-type channels present in axons were diffusely distributed with some degree of enrichment in zones of contacts between axons and dendrites of neighboring nontransfected cells (Fig. $1 B$ ). Similar results were obtained with another $\alpha_{1 \mathrm{~B}}$ construct in which HA tag was inserted into the intracellular loop between II and III repeats (data not shown). Thus, targeting of $\mathrm{N}$-type channels in neurons is not likely to be affected by addition of the N-terminal HA tag.

Overexpression of recombinant N-type channels in neurons may lead to an artificially strong signal from the channels retained in somatic intracellular compartments, primarily the ER. Surface labeling experiments can help to visualize channels in the plasma membrane. We attempted to incorporate surface-accessible myc tag into several putative extracellular loops in the $\alpha_{1 \mathrm{~B}}$ sequence, but these constructs could not be detected by anti-myc antibodies in neuronal surface labeling experiments (data not shown). Presumably, myc epitope in these positions is not accessible to the antibody. Instead, we used confocal imaging to determine subcellular localization of the HA- $\alpha_{1 \mathrm{~B}}$ subunit. As expected from the Xenopus oocyte expression experiments (see Materials and Methods; Table 1), obtained images were not consistent with the ER-trapped HA- $\alpha_{1 \mathrm{~B}}$ subunit (Fig. 1D). Thus, we concluded that recombinant $\mathrm{N}$-type channels are uniformly distributed in immature hippocampal neurons, in agreement with the previously reported studies of native N-type channel distribution in immature hippocampal neurons using immunolocalization (Bahls et al., 1998) and functional (Pravettoni et al., 2000) methods.

\section{Distribution of $\mathrm{N}$-type $\mathrm{Ca}^{2+}$ channels in mature rat hippocampal neurons}

Neuronal contact-dependent clustering of endogenous N-type $\mathrm{Ca}^{2+}$ channels (Bahls et al., 1998) and synapsins (Fletcher et al., 1991) in synaptic sites has been described for mature high-density cultures of rat hippocampal neurons. Thus, we subsequently ex- 

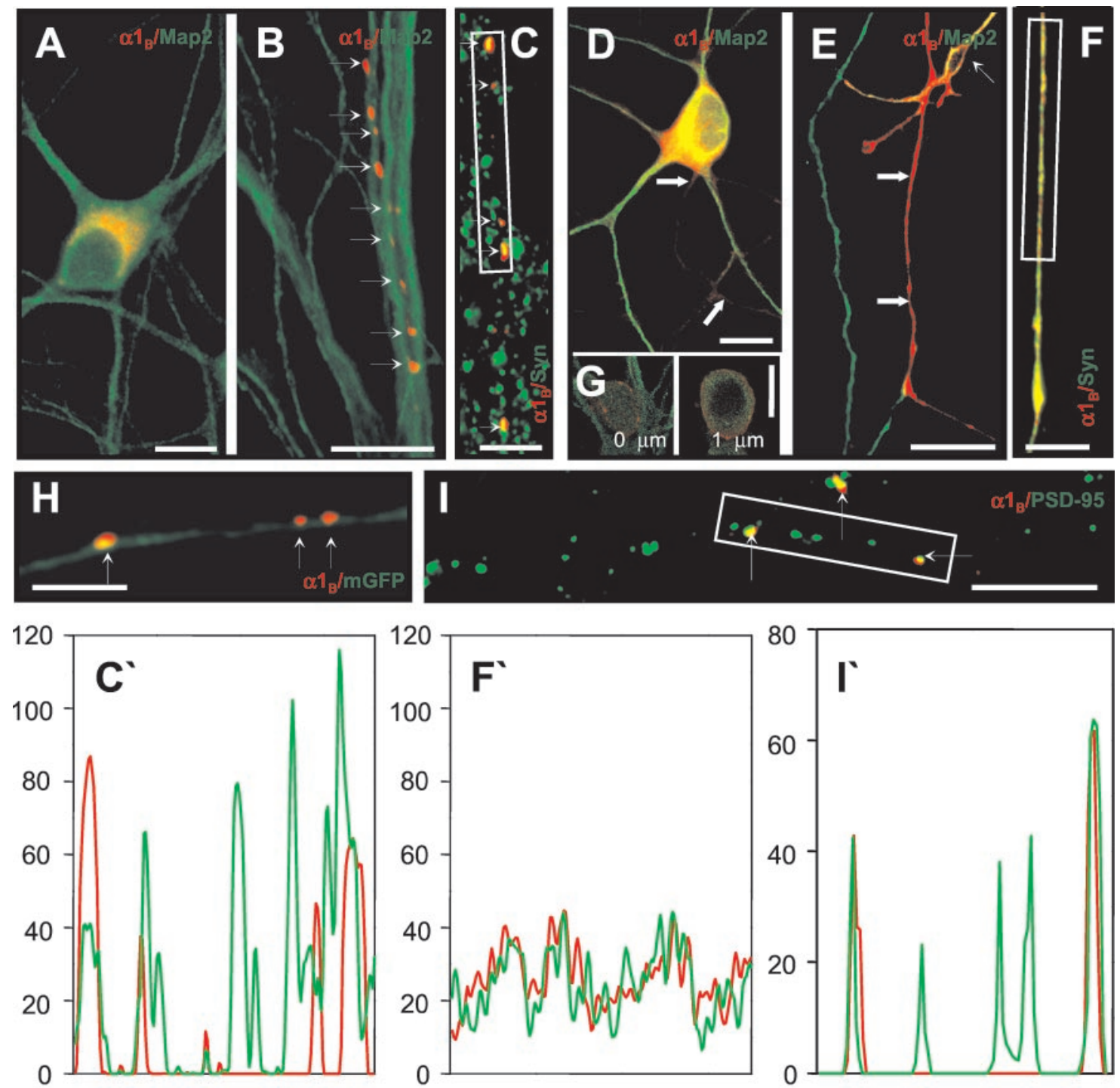

Figure 2. Distribution of recombinant N-type channels in mature hippocampal neurons. Neurons cultured at high $(A-C, H, I)$ or low $(D-G)$ density were transfected with an HA- $\alpha_{1 \mathrm{~B}} / \alpha_{2} \delta / \beta_{3}$ plasmid combination at $10 \mathrm{DIV}$ and analyzed $96 \mathrm{hr}$ after transfection. $A$, $B$, Staining for HA- $\alpha_{1 \mathrm{~B}}($ red $)$ and MAP2 (green) of hippocampal neurons cultured at high density for $14 \mathrm{~d}$ (14 DIV). The recombinant channels are primarily excluded from somatodendritic domain $(A)$ and concentrated in discrete clusters apposed to dendrites of nontransfected cells $(B$, small arrows). Scale bars, $20 \mu \mathrm{m}$. $C$, Colocalization of HA- $\alpha_{1 \mathrm{~B}}$ clusters (red, small arrows) with clusters of endogenous synapsin (green) in axons of 14 DIV hippocampal neurons cultured at high density. The fluorescence intensity profile $\left(C^{\prime}\right.$; HA, red; synapsin, green $)$ is taken from the boxed area in $C$. HA-negative clusters of synapsin correspond to synaptic terminals of nontransfected neurons in the field of view. Scale bar, $10 \mu \mathrm{m} . D, E$, Staining for HA- $\alpha_{1 \mathrm{~B}}$ (red) and MAP2 (green) of neurons cultured at low density for $14 \mathrm{~d}$. The N-type channels are present in the somatodendritic domain $(D)$ and uniformly distributed in axons $(E)$. The axons (large arrows) are identified as MAP2-negative processes. Weak HA- $\alpha_{1 \mathrm{~B}}$ immunoreactivity is observed in the proximal axonal segment $(D)$, but a strong HA signal was observed in distal parts of axons $(E)$ and growth cones (data now shown). In $E$, a dendrite (MAP2-positive) of a neighboring transfected cell in indicated by a small arrow. Scale bars, $20 \mu \mathrm{m}$. F, Distribution of recombinant HA- $\alpha_{1 \mathrm{~B}}($ red $)$ and endogenous synapsin $($ green $)$ in axons of 14 DIV hippocampal neurons cultured at low density. The fluorescence intensity profile $\left(F^{\prime}\right.$; HA, red; synapsin, green $)$ is taken from the boxed area in $F$. Scale bar, $10 \mu \mathrm{m}$. $G$, Confocal analysis of recombinant HA- $\alpha_{1 \mathrm{~B}}$ localization in the soma of mature neurons cultured at low density. HA- $\alpha_{1 \mathrm{~B}}$ is shown in red; MAP2 is in green. Images were collected as described in Figure $1 D$ and Materials and Methods. Two representative images from the stack are shown. $H$, Axon of a neuron cotransfected with HA- $\alpha_{1 \mathrm{~B}} / \alpha_{2} \delta / \beta_{3}$ (red) and mGFP ( green). Clusters of HA- $\alpha_{1 \mathrm{~B}}$ are indicated by small arrows. Scale bar, $10 \mu \mathrm{m}$. I, Clusters of recombinant HA- $\alpha_{1 \mathrm{~B}}$ (red) and endogenous PSD-95 ( green) colocalize (small arrows). The fluorescence intensity profile $\left(I^{\prime} ; \mathrm{HA}\right.$, red; PSD-95, green) is taken from the boxed area in I. HA-negative clusters of PSD-95 correspond to synaptic terminals of nontransfected neurons in the field of view. Scale bar, $10 \mu \mathrm{m}$.

amined the distribution of recombinant N-type $\mathrm{Ca}^{2+}$ channels (HA- $\left.\alpha_{1 \mathrm{~B}} / \alpha_{2} \delta / \beta_{3}\right)$ in high-density mature (14 DIV) rat hippocampal neuronal cultures. In contrast to experiments with immature cultures, we found that in mature cultures $\mathrm{HA}-\alpha_{1 \mathrm{~B}}$ was primarily absent from soma and dendrites (Fig. 2A). Indeed, in $90 \pm 5 \%$ ( $n=110$; five independent transfections) of neurons only weak HA immunoreactivity was detected in soma and proximal den- drites (Fig. 2A). Recombinant N-type channels expressed in mature neuronal cultures were concentrated in discrete clusters apposed to dendrites of nontransfected cells (Fig. 2B). When the neurons were cotransfected with recombinant $\mathrm{N}$-type $\mathrm{Ca}^{2+}$ channels and the membrane-associated form of GFP (mGFP) (Moriyoshi et al., 1996), the HA- $\alpha_{1 \mathrm{~B}}$-positive clusters were associated with the long, fine caliber fibers visualized by mGFP 
fluorescence (Fig. 2H). The latter observation rules out the possibility that the clusters of $\mathrm{HA}-\alpha_{1 \mathrm{~B}}$ represent protein aggregates formed because of toxicity or fragmentation of neuronal processes. The morphology of neuronal processes visualized by mGFP fits with the expected morphology of axonal processes at the corresponding stage of neuronal culture (Fletcher and Banker, 1989). The HA- $\alpha_{1 \mathrm{~B}}$-positive clusters were localized to contacts between axon (MAP2-negative) and dendrites (MAP2positive) processes (Fig. $2 B$ ). The HA- $\alpha_{1 \mathrm{~B}}$-positive clusters were also precisely colocalized with the clusters of endogenous synapsin (Fig. 2C, $C^{\prime}$ ) and endogenous PSD-95 (Fig. 2I, $I^{\prime}$ ), visualized by the corresponding polyclonal antibody. From all of these results, we concluded that the recombinant $\mathrm{N}$-type $\mathrm{Ca}^{2+}$ channels expressed in mature neuronal cultures are concentrated in axons and clustered at presynaptic locations.

Distribution of recombinant N-type channels was diffuse and uniform in immature, low-density neuronal cultures (Fig. 1A,B) and punctate and polarized in mature, high-density cultures (Fig. $2 A-C, H, I)$. Is distribution of recombinant N-type channels in neurons affected by the age of neuronal culture or by the formation of synapses? To answer this question, we transfected lowdensity rat hippocampal neuronal cultures at $10 \mathrm{DIV}$ with the HA- $\alpha_{1 \mathrm{~B}} / \alpha_{2} \delta / \beta_{3}$ subunit combination and analyzed HA- $\alpha_{1 \mathrm{~B}}$ localization $4 \mathrm{~d}$ after transfection. At the same age of culture, the number of synaptic contacts formed by each cell in the lowdensity culture was significantly reduced when compared with the high-density culture. The N-type channels expressed in the lowdensity mature cultures were diffusely distributed in soma, dendrites, and axons of transfected neurons (Fig. 2D,E). Using confocal imaging, we demonstrated that the immunoreactivity in the somatic compartment does not result from ER-trapped HA- $\alpha_{1 \mathrm{~B}}$ protein (Fig. 2G). Axons in these experiments can be easily identified as HA- $\alpha_{1 \mathrm{~B}}$-positive MAP2-negative processes (Fig. $2 E$ ). In agreement with previous findings (Fletcher et al., 1991), distribution of endogenous synapsins in axons of these neurons had a granular appearance (Fig. $2 F$ ), in marked contrast to distinct clusters of synapsin observed in mature high-density cultures (Fig. $2 C$ ). Distribution of HA- $\alpha_{1 \mathrm{~B}}$ in axons of neurons cultured at low density was similar to distribution of synapsin (Fig. $2 F, F^{\prime}$ ). We concluded from these experiments that neuronal contacts and synapse formation are essential for recombinant $\mathrm{N}$-type $\mathrm{Ca}^{2+}$ channel clustering in hippocampal neurons. It also appears that not only synaptic clustering but also polarized distribution of recombinant $\mathrm{N}$-type $\mathrm{Ca}^{2+}$ channels depends on neuronal contacts (Fig. 2A,D). The latter conclusion is unexpected and challenges a common view that polarized protein targeting in neurons is guided by intrinsic sorting signals and happens independently of cell-to-cell contacts (Craig and Banker, 1994).

\section{Structural determinants of $\mathrm{N}$-type $\mathrm{Ca}^{2+}$ channel targeting to synapse}

In the next series of experiments, we searched for the structural determinants responsible for $\mathrm{N}$-type $\mathrm{Ca}^{2+}$ channel targeting to synapses. In the previous biochemical studies, we identified $\mathrm{SH} 3$ and PDZ domain-binding motifs in the $\mathrm{C}$-terminal region of the long splice variant of a human $\mathrm{N}$-type $\mathrm{Ca}^{2+}$ channel poreforming subunit, $\alpha_{1 \mathrm{~B}-1}\left(\mathrm{Ca}_{\mathrm{V}} 2.2 \mathrm{a}\right)$ (Maximov et al., 1999). We discovered (Maximov et al., 1999) that Mint1-PDZ1 binds to the C termini of the $\alpha_{1 \mathrm{~B}}$ subunit (Fig. $3 A$, black box, diagram), and that CASK-SH3 binds to the proline-rich region $\sim 300$ aa upstream of the $\alpha_{1 \mathrm{~B}} \mathrm{C}$ termini (Fig. $3 A$, dashed box, diagram). The same proline-rich region has been also implicated in interactions with G-protein $\beta \gamma$ subunits (Qin et al., 1997), with the auxiliary $\mathrm{Ca}^{2+}$ channel $\beta$ subunit (Walker et al., 1998) and more recently with the SH3 domain of the Rab3-interacting molecule (RIM)binding protein (RBP) (Hibino et al., 2002). We hypothesized previously that the identified $\mathrm{PDZ}$ and $\mathrm{SH} 3$ domain-binding motifs may play a role in $\mathrm{N}$-type $\mathrm{Ca}^{2+}$ channel synaptic targeting in neurons (Maximov et al., 1999). To test this hypothesis, a series of C-terminal mutants of HA-tagged $\alpha_{1 \mathrm{~B}}$ subunit was generated and expressed in mature, high-density hippocampal cultures (Fig. 3). The $\alpha_{1 \mathrm{~B}}$ mutants used in these experiments were expressed at levels similar to the wild-type channels when transfected into COS7 or HEK293 cells and supported functional $\mathrm{Ca}^{2+}$ currents of similar size when expressed in Xenopus oocytes (see Materials and Methods; Table 1).

As discussed in the previous section, the wild-type HA- $\alpha_{1 \mathrm{~B}}$ subunit expressed in mature high-density cultures was localized in clusters along axonal processes and precisely colocalized with endogenous synapsins (Fig. $3 A$ ). Axonal clustering of the wildtype HA- $\alpha_{1 \mathrm{~B}}$ subunit was observed in $95 \pm 3 \%(n=27)$ of transfected neurons (Fig. $3 F$ ). In contrast, the HA- $\alpha_{1 \mathrm{~B}}-\mathrm{T} 2038 \mathrm{X}$ truncation mutant was diffusely distributed along the axonal processes (Fig. 3B,F). Thus, the last 301 aa of the $\alpha_{1 \mathrm{~B}}$ sequence (amino acids 2038-2339) did indeed contain motifs essential for synaptic targeting of recombinant $\mathrm{N}$-type $\mathrm{Ca}^{2+}$ channels in hippocampal neurons. To determine the role played by the PDZ domain-binding motif, we generated the HA- $\alpha_{1 \mathrm{~B}}-\mathrm{D} 2334 \mathrm{X}$ mutant that lacks the last $6 \mathrm{C}$-terminal amino acids of the $\alpha_{1 \mathrm{~B}}$ sequence. When the HA- $\alpha_{1 \mathrm{~B}}$-D2334X mutant was expressed in neurons, it also formed synaptic clusters along the axonal processes (Fig. 3C). The synaptic clustering of the HA- $\alpha_{1 \mathrm{~B}}$-D2334X mutant was observed only in $48 \pm 3 \%(n=21)$ of transfected cells (Fig. $3 F)$, indicating partial impairment of channel targeting caused by C-terminal truncation.

Alternative splicing of human $\alpha_{1 \mathrm{~B}} \mathrm{C}$ termini occurs within the proline-rich region at position 2163 (Williams et al., 1992). The HA- $\alpha_{1 \mathrm{~B}}$-S2176X mutant, truncated close to the alternative splicing site of human $\alpha_{1 \mathrm{~B}}$ subunit, is diff usely distributed in axons of transfected neurons (Fig. $3 F$ ). We noticed that a strong class I SH3 domain-binding consensus ${ }^{2188} R Q L P Q T P L T P R P P^{2199}$ (Dalgarno et al., 1997; Mayer, 2001) is present in the $\alpha_{1 \mathrm{~B}-1}\left(\mathrm{Ca}_{\mathrm{V}} 2.2 \mathrm{a}\right)$ but not in the $\alpha_{1 \mathrm{~B}-2}\left(\mathrm{Ca}_{\mathrm{V}} 2.2 \mathrm{~b}\right)$ isoform of the human subunit. We reasoned that this motif may play an important role in channel targeting and replaced its portion (amino acids 2191-2199) with the polyalanine sequence (PXXP-A mutation) (Fig. 3D, diagram, gap). In control biochemical experiments, we established that the region of $\alpha_{1 \mathrm{~B}}$ subunit involved in association with the $\beta_{3}$ subunit lies upstream of the area affected by the PXXP-A mutation (data not shown). Notably, the PXXP-A mutation is expected to affect the association of $\alpha_{1 \mathrm{~B}}$ subunit with the RBP-SH3 domain, which binds to the same motif (Hibino et al., 2002). When the HA- $\alpha_{1 \mathrm{~B}}$ PXXP-A mutant was expressed in mature neuronal cultures, synaptic clustering of recombinant channels was observed in $59 \pm$ $1 \%$ of transfected cells (Fig. $3 F$ ). Thus, the phenotype of the HA- $\alpha_{1 \mathrm{~B}}$-PXXP-A mutant is very similar to the phenotype of the HA- $\alpha_{1 \mathrm{~B}}-\mathrm{D} 2334 \mathrm{X}$ mutant; in both cases, the channels are clustered at synapses, albeit not as efficiently as the wild-type channel (Fig. $3 F$ ).

To further investigate the targeting function of PDZ and SH3 domain-binding motifs in the $\alpha_{1 \mathrm{~B}}$ C-terminal region, we combined the PXXP-A and D2334X mutations. When the resulting HA-tagged double mutant was expressed in hippocampal neurons, diffuse distribution of recombinant $\mathrm{N}$-type channels in 

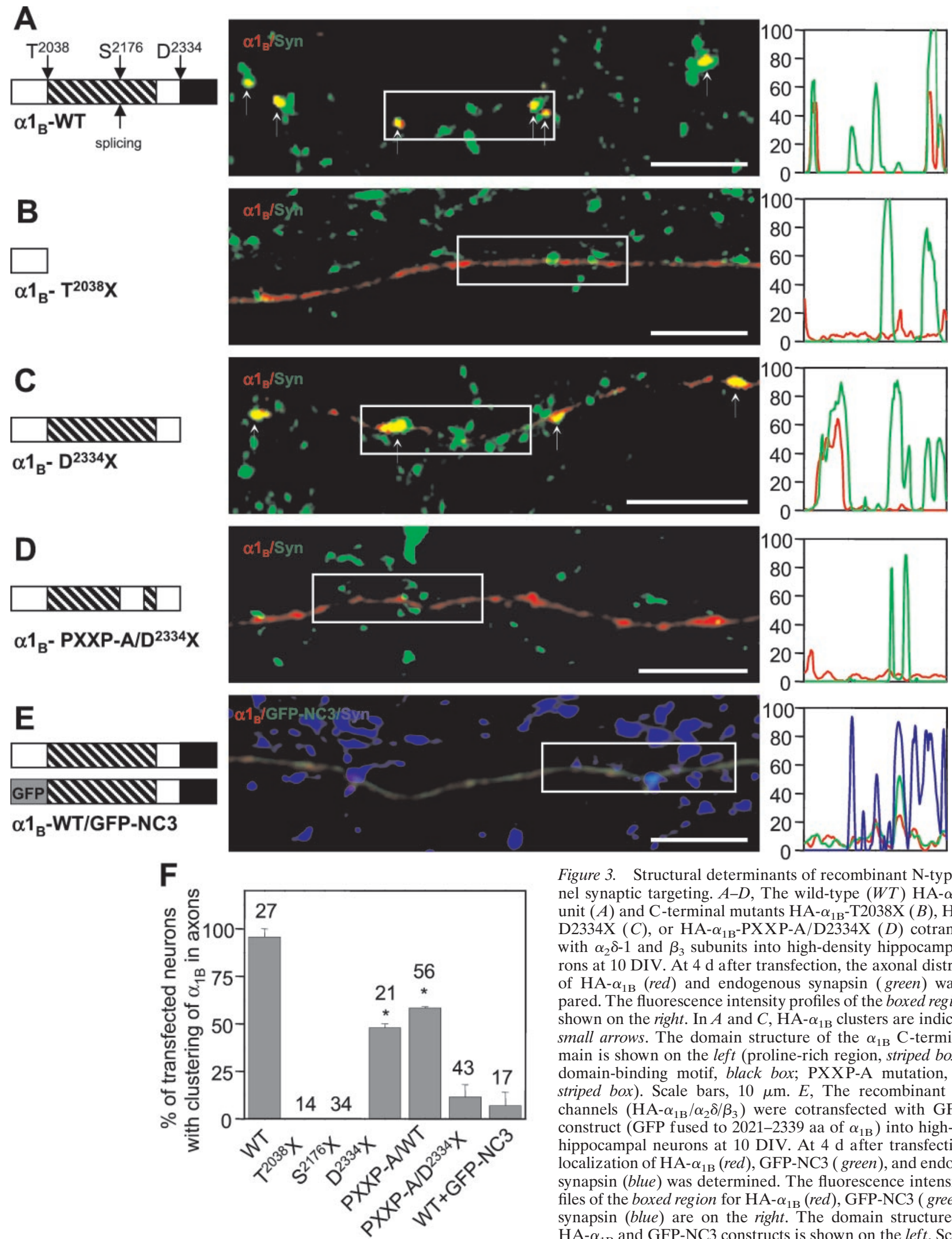

Figure 3. Structural determinants of recombinant N-type channel synaptic targeting. $A-D$, The wild-type $(W T) \mathrm{HA}-\alpha_{1 \mathrm{~B}}$ subunit $(A)$ and $\mathrm{C}$-terminal mutants HA- $\alpha_{1 \mathrm{~B}^{-}} \mathrm{T} 2038 \mathrm{X}(B), \mathrm{HA}-\alpha_{1 \mathrm{~B}^{-}}$ D2334X $(C)$, or HA- $\alpha_{1 \mathrm{~B}}-\mathrm{PXXP}-\mathrm{A} / \mathrm{D} 2334 \mathrm{X}(D)$ cotransfected with $\alpha_{2} \delta$ - 1 and $\beta_{3}$ subunits into high-density hippocampal neurons at 10 DIV. At $4 \mathrm{~d}$ after transfection, the axonal distribution of HA- $\alpha_{1 \mathrm{~B}}$ (red) and endogenous synapsin (green) was compared. The fluorescence intensity profiles of the boxed regions are shown on the right. In $A$ and $C, \mathrm{HA}-\alpha_{1 \mathrm{~B}}$ clusters are indicated by small arrows. The domain structure of the $\alpha_{1 \mathrm{~B}} \mathrm{C}$-terminal domain is shown on the left (proline-rich region, striped box; PDZ domain-binding motif, black box; PXXP-A mutation, gap in striped box). Scale bars, $10 \mu \mathrm{m}$. E, The recombinant N-type channels (HA- $\left.\alpha_{1 \mathrm{~B}} / \alpha_{2} \delta / \beta_{3}\right)$ were cotransfected with GFP-NC3 construct (GFP fused to 2021-2339 aa of $\alpha_{1 \mathrm{~B}}$ ) into high-density hippocampal neurons at $10 \mathrm{DIV}$. At $4 \mathrm{~d}$ after transfection, the localization of $\mathrm{HA}-\alpha_{1 \mathrm{~B}}($ red $)$, GFP-NC3 ( green), and endogenous synapsin (blue) was determined. The fluorescence intensity profiles of the boxed region for $\mathrm{HA}-\alpha_{1 \mathrm{~B}}$ (red), GFP-NC3 (green), and synapsin (blue) are on the right. The domain structure of the HA- $\alpha_{1 \mathrm{~B}}$ and GFP-NC3 constructs is shown on the left. Scale bar, $10 \mu \mathrm{m} . F$, Quantitative analysis of HA- $\alpha_{1 \mathrm{~B}}$ wild-type and C-terminal mutant axonal distribution. Based on visual examination, for each transfected neuron the axonal distribution of $\mathrm{HA}-\alpha_{1 \mathrm{~B}}$ was scored as clustered or diff use. The percentage of transfected neurons with clustered axonal distribution of HA- $\alpha_{1 \mathrm{~B}}$ was calculated for each transfection. The data from at least two independent transfections for each construct are presented as mean \pm SD, with the total numbers of analyzed cells shown on the top. For D2334X and PXXP-A mutants, the $p$ values (when compared with the wild type) are $<0.002$ and 0.01 , respectively (indicated by asterisks). 
axons was observed (Fig. $3 D$ ), similar to the HA- $\alpha_{1 \mathrm{~B}}-\mathrm{T} 2038 \mathrm{X}$ truncation mutant (Fig. $3 B$ ). Axonal clusters were observed only in $12 \pm 9 \%$ of neurons transfected with the HA- $\alpha_{1 \mathrm{~B}}-\mathrm{PXXP}-\mathrm{A} /$ D2334X double mutant (Fig. $3 F$ ). Thus, deletion of a 6-aa-long PDZ domain-binding consensus (2334-2339) and mutation of a 9-aa-long SH3 domain-binding consensus (2191-2199) to polyalanines results in an almost complete loss of the ability of the N-type channel to cluster at synapses in hippocampal neurons. We concluded that PDZ and SH3 domain-binding motifs in $\alpha_{1 \mathrm{~B}-1}$ $\mathrm{C}$ termini act as synergistic synaptic targeting signals, and that the presence of at least one of these motifs is necessary for synaptic targeting of $\mathrm{N}$-type $\mathrm{Ca}^{2+}$ channels.

The most likely explanation for our results is that interaction of the $\alpha_{1 \mathrm{~B}}$ subunit with endogenous adaptor proteins containing PDZ and SH3 domains is required for synaptic targeting of $\mathrm{N}$-type channels. If this is indeed the case, then overexpression of the C-terminal portion of the $\alpha_{1 \mathrm{~B}}$ subunit that contains the PDZ and SH3 domain-binding motifs in neurons should result in competition for adaptor proteins and cause mislocalization of N-type channels. To test this hypothesis, we coexpressed the GFP-NC3 construct (GFP fused to the $\alpha_{1 \mathrm{~B}}$ fragment between amino acids 2021-2339) (Fig. 3E, diagram) with HA-tagged recombinant N-type $\mathrm{Ca}^{2+}$ channels $\left(\mathrm{HA}-\alpha_{1 \mathrm{~B}} / \alpha_{2} \delta / \beta_{3}\right)$ in mature (14 DIV) neuronal cultures. In agreement with our prediction, the formation of HA-positive clusters but not clusters of endogenous synapsins was abolished in GFP-NC3-expressing axons (Fig. $3 E, F)$. The effect of GFP-NC3 was specific, because coexpression with $\mathrm{mGFP}$ did not interfere with synaptic clustering of recombinant N-type channels (Fig. $2 H$ ). We reasoned that GFP-NC3 exerts its dominant-negative effect by displacing $\mathrm{HA}-\alpha_{1 \mathrm{~B}}$ from complexes with endogenous adaptor proteins involved in synaptic cluster formation.

\section{Alternative splicing of rat $\alpha_{1 \mathrm{~B}}$ subunit}

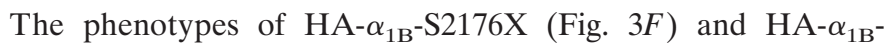
PXXP-A/D2334X (Fig. 3D,F) mutants suggest that only the long $\alpha_{1 \mathrm{~B}}-\mathrm{NC} 1 \quad\left(\alpha_{1 \mathrm{~B}-1}, \mathrm{Ca}_{\mathrm{V}} 2.2 \mathrm{a}\right)$ but not "short" $\alpha_{1 \mathrm{~B}}-\mathrm{NC} 2\left(\alpha_{1 \mathrm{~B}-2}\right.$, $\left.\mathrm{Ca}_{\mathrm{V}} 2.2 \mathrm{~b}\right)$ splice variant of $\alpha_{1 \mathrm{~B}}$ subunit should be targeted to synapses. To test this hypothesis experimentally, we set out to clone the rat $\alpha_{1 \mathrm{~B}} \mathrm{NC2}$ splice variant (rNC2). The short $\mathrm{C}$-tail splice isoform of rat $\alpha_{1 \mathrm{~B}}$ was observed in biochemical experiments (Hell et al., 1994), but only the rNC1 isoform sequence is present in the GenBank database. By standard molecular techniques, we isolated rat brain mRNA, synthesized cDNA from oligo-dT primer, and performed a nested PCR with two pairs of rat $\alpha_{1 \mathrm{~B}}$-specific primers (see Materials and Methods). Two distinct products obtained as a result of a nested PCR were isolated, subcloned, and sequenced. One product corresponded to a known rNC1 isoform of rat $\alpha_{1 \mathrm{~B}}$ subunit (Dubel et al., 1992). Another product corresponded to a novel rNC2 $\left(\alpha_{1 \mathrm{~B}-2}, \mathrm{Ca}_{\mathrm{V}} 2.2 \mathrm{~b}\right)$ isoform (GenBank accession number AF389419). Interestingly, the position of the $\mathrm{C}$-terminal splicing site and the sequence of $\alpha_{1 \mathrm{~B}}-\mathrm{NC} 1$ isoform is highly conserved between human (Williams et al., 1992), chicken (Lu and Dunlap, 1999), and rat (Fig. 4A) clones, whereas the sequence of the $\alpha_{1 \mathrm{~B}}-\mathrm{NC} 2$ isoform after the splicing site is divergent between species.

To obtain information about localization of the $\alpha_{1 \mathrm{~B}}-\mathrm{NC} 2$ isoform in neurons, we fused the $\mathrm{C}$-terminal tail of the short rat $\alpha_{1 \mathrm{~B}} \mathrm{NC} 2$ splice variant with the HA-tagged human $\alpha_{1 \mathrm{~B}}$ clone. The resulting HA- $\alpha_{1 \mathrm{~B}}$-rNC2 construct was coexpressed with auxiliary $\alpha_{2 \delta}$ and $\beta_{3}$ subunits in immature (5-6 DIV) (data not shown) and mature (14 DIV) (Fig. 4B) high-density rat hip- pocampal neurons. We found that the short HA- $\alpha_{1 \mathrm{~B}}-\mathrm{rNC} 2$ splice variant was primarily excluded from axons of both immature (data not shown) and mature neurons and formed aggregates in neuronal soma and proximal dendrites (Fig. 4B). Confocal image analysis (Fig. 4C) and Xenopus oocyte expression experiments (see Materials and Methods; Table 1) confirmed that the HA$\alpha_{1 \mathrm{~B}}-\mathrm{rNC} 2$ protein was not trapped in the ER. The localization of the HA- $\alpha_{1 \mathrm{~B}}-\mathrm{rNC} 2$ isoform in mature high-density neuronal cultures differs dramatically from the localization of the HA- $\alpha_{1 \mathrm{~B}}$ $\mathrm{NC} 1$ isoform (Fig. $2 A-C$ ). The distribution of $\mathrm{HA}-\alpha_{1 \mathrm{~B}}-\mathrm{rNC} 2$ also differs from the distribution of $\mathrm{HA}-\alpha_{1 \mathrm{~B}}-\mathrm{T} 2038 \mathrm{X}$ and $\mathrm{HA}-\alpha_{1 \mathrm{~B}^{-}}$ S2176X truncation mutants, which were diffusely and uniformly distributed in both axonal (Fig. 3B,F) and somatodendritic (data not shown) domains. Thus, somatodendritic retention and aggregation motifs are likely to be encoded by $\mathrm{C}$ termini of the $\alpha_{1 \mathrm{~B}}$ NC2 splice variant. From these results, we concluded that the $\alpha_{1 \mathrm{~B}}-\mathrm{NC} 1\left(\alpha_{1 \mathrm{~B}-1}, \mathrm{Ca}_{\mathrm{V}} 2.2 \mathrm{a}\right)$ splice variant encodes the axonal/ synaptic isoform, and that the $\alpha_{1 \mathrm{~B}}-\mathrm{NC} 2\left(\alpha_{1 \mathrm{~B}-2}, \mathrm{Ca}_{\mathrm{V}} 2.2 \mathrm{~b}\right)$ splice variant encodes the somatodendritic isoform of the $\mathrm{N}$-type $\mathrm{Ca}^{2+}$ channels.

To test this hypothesis further, we generated NC1 splicevariant-specific antibodies against the $\mathrm{C}$-terminal region of the rat $\alpha_{1 \mathrm{~B}}$ subunit (see Materials and Methods). Generated NC1 antibodies were not appropriate for immunostaining of hippocampal cultures (data not shown). However, NC1 antibodies could be used for Western blotting and immunoprecipitation experiments. To analyze the subcellular distribution of the NC1 splice variant, we fractionated rat brain cortical homogenate (Jones and Matus, 1974) and analyzed the resulting fractions by Western blotting with NC1 antibodies (Fig. 4D, first row), PSD-95 antibodies (Fig. $4 D$, second row), synapsin I antibodies (Fig. 4D, third row), and MAP2 antibodies (Fig. 4D, fourth row). We found that the distribution of NC1 immunoreactivity was parallel to that of PSD-95 (Fig. 4D), suggesting that the endogenous NC1 splice variant is concentrated in synaptic locations. What is a relative distribution of NC1 and NC2 splice variants? We could not generate NC2-specific antibodies to address this question directly. Instead, we performed experiments with $\mathrm{NN}$ antibodies directed against the $\mathrm{N}$-terminal region of the rat $\alpha_{1 \mathrm{~B}}$ subunit (Maximov et al., 1999). The NN antibodies recognized both C-terminal splice variants of the rat $\alpha_{1 \mathrm{~B}}$ subunit. To quantify the relative distribution of NC1 and NC2 splice variants, in the next series of experiments we compared the relative ability of $\mathrm{NC} 1$ and $\mathrm{NN}$ antibodies to immunoprecipitate ${ }^{125} \mathrm{I}-\omega$-GVIA-labeled N-type $\mathrm{Ca}^{2+}$ channels from different subcellular fractions. We found that the fraction of ${ }^{125} \mathrm{I}-\omega$-GVIA binding sites precipitated by NC1 antibodies from the SPM fraction was significantly elevated when compared with $\mathrm{P} 2$ and $\mathrm{P} 3$ fractions (Fig. 4E). Thus, we concluded that the $\mathrm{NC1}$ splice variant is enriched in synaptic locations in comparison with the NC2 splice variant.

\section{Dominant negative effects of $\alpha_{1 \mathrm{~B}} \mathrm{C}$ termini on synaptic function}

The C-terminal GFP-NC3 construct disrupts the synaptic clustering of recombinant $\mathrm{N}$-type $\mathrm{Ca}^{2+}$ channels (Fig. $3 E, F$ ). In the next series of experiments, we analyzed the effects of GFP-NC3 overexpression on synaptic function. To measure synaptic activity, we monitored the depolarization-induced uptake of antibodies against the lumenal domain of STI in synapses of hippocampal neurons. In these experiments, we followed the previously de- 
A

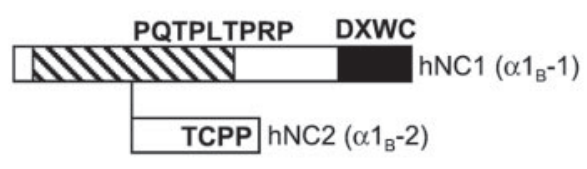

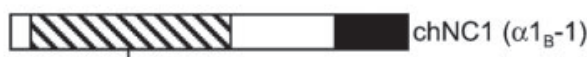

WFG $\operatorname{chNC2}\left(\alpha 1_{B}-2\right)$
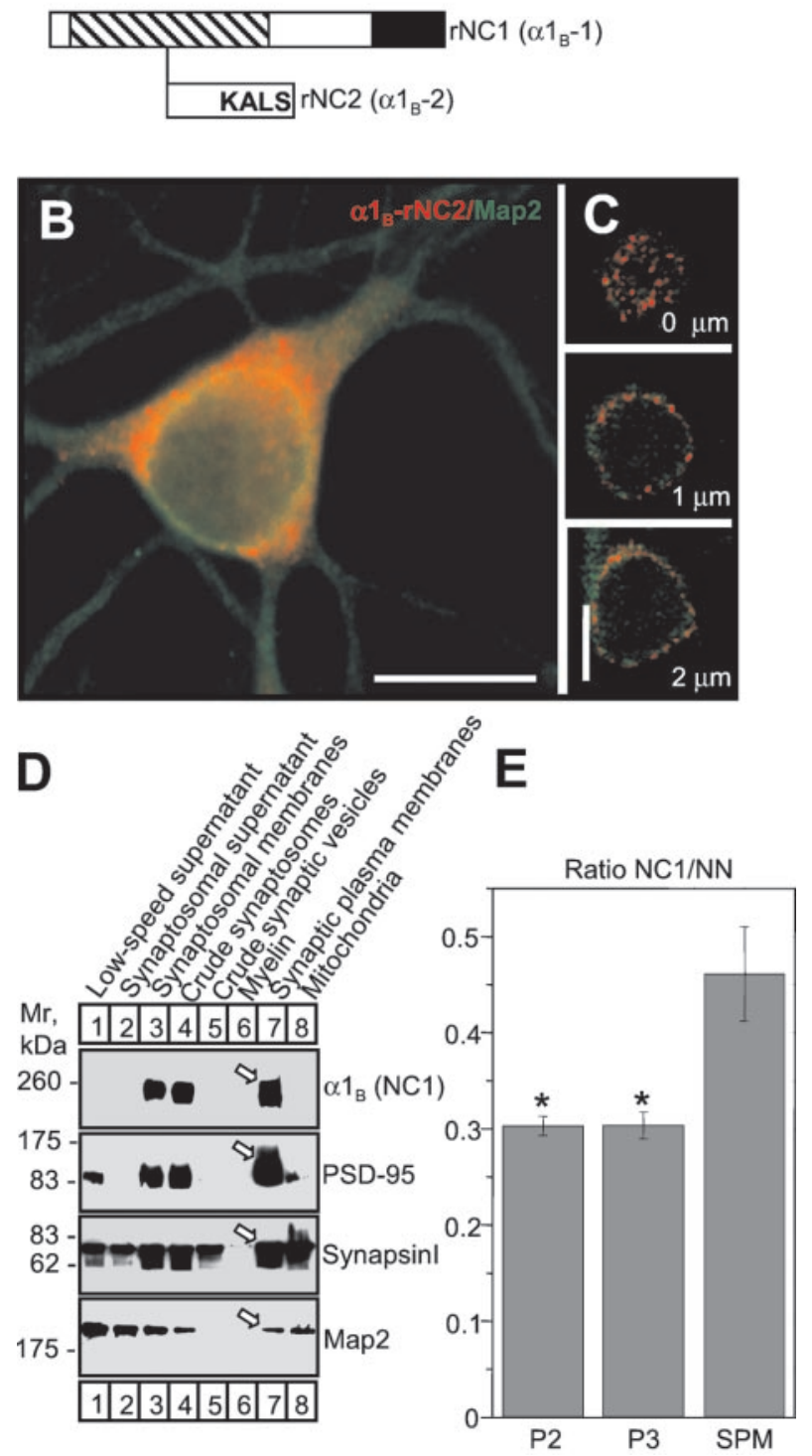

Figure 4. Cloning and subcellular localization of rat $\alpha_{1 \mathrm{~B}}-\mathrm{NC} 2$ splice variant. $A$, Diagram of human (Williams et al., 1992), chicken (Lu and Dunlap, 1999), and rat $\alpha_{1 \mathrm{~B}} \mathrm{C}$-terminal splice variants. The sequence of rat $\alpha_{1 \mathrm{~B}}-\mathrm{NC} 2$ has been deposited in GenBank (accession number AF389419). The position of PDZ and SH3 domain-binding motifs is indicated as in Figure $3 A$. $B$, Recombinant HA- $\alpha_{1 \mathrm{~B}}$-rNC2 (red) and endogenous MAP2 (green) localization in mature neurons cultured at high density. Scale bars, $20 \mu \mathrm{m}$. $C$, Confocal analysis of recombinant $\mathrm{HA}-\alpha_{1 \mathrm{~B}}-\mathrm{rNC} 2$ localization in the soma of mature neurons cultured at low density. Three representative images from the stack are shown. $D$, Western blot of rat brain subcellular fractions with antibodies against rat $\alpha_{1 \mathrm{~B}}-\mathrm{NC} 1$ and the neuronal markers PSD-95, synapsin I, and MAP2. Equal amounts of protein were loaded to each lane. Arrows indicate samples on the synaptic plasma membrane fraction. $E$, The ratio of ${ }^{125} \mathrm{I}-\omega$-GVIA binding site amounts precipitated by $\mathrm{NC} 1$ and $\mathrm{NN}$ antibodies from P2, P3, and SPM fractions solubilized in CHAPS. ${ }^{*} p<0.001$. scribed STI labeling procedure (Matteoli et al., 1992) (Fig. 5A). The STI antibodies, trapped inside endocytosed synaptic vesicles, report locations of synapses capable of depolarization-induced exocytosis. Opening of synaptic voltage-gated $\mathrm{Ca}^{2+}$ channels and $\mathrm{Ca}^{2+}$ influx into the presynaptic terminal is an essential step leading from depolarization to exocytosis. When extracellular $\mathrm{Ca}^{2+}$ was omitted from depolarization media, no signal with STI antibodies was observed in response to $\mathrm{KCl}$ depolarization (data not shown). In additional control experiments, we demonstrated that STI-positive clusters were concentrated in points of contact between axons and the MAP2-positive postsynaptic target (Fig. $5 B)$, and that STI- and synapsin-positive clusters were colocalized (Fig. 5C), confirming the specificity of the STI staining pattern.

To test the effect of GFP-NC3 overexpression on synaptic function, we compared the signal reported by STI antibodies for nontransfected (control) neurons and for neurons transfected with GFP-NC3 or mGFP. When compared with control neurons, we observed a significant reduction in the intensity of individual STI-positive clusters in axons expressing GFP-NC3 (Fig. 5D, $D^{\prime}$ ) but not in axons expressing mGFP (Fig. $5 E$ ). On average, the intensity of STI-positive clusters was $40 \%$ weaker in axons of GFP-NC3-transfected cells than in the axons of nontransfected or mGFP-expressing cells (Fig. $5 F$ ). The effect of GFP-NC3 on STI staining was not caused by loss of the ability of the axons of transfected neurons to form synaptic contacts, because synapsin and PSD-95 staining was not affected by GFP-NC3 overexpression (Fig. $5 F$ ). A similar conclusion can be drawn by comparing the cumulative distribution of individual STI cluster intensities between control, mGFP-expressing, and GFP-NC3-expressing neurons (Fig. 5G). We reasoned from these data that depolarization-induced exocytosis is suppressed in synapses of neurons overexpressing GFP-NC3 but not mGFP construct. To explain these results, we reasoned that depression of synaptic function by the GFP-NC3 construct is caused by its interference with targeting and/or the synaptic function of endogenous $\mathrm{Ca}^{2+}$ channels in hippocampal neuronal cultures.

Overexpression of GFP-NC3 completely abolished the clustering of recombinant N-type channels (Fig. 3E,F) but had only a partial effect on the synaptic activity reported by STI antibody uptake (Fig. 5F). Previous experiments with FM1-43 imaging dye indicated that in hippocampal neuronal cultures $\sim 45 \%$ of synapses rely solely on $\mathrm{N}$-type $\mathrm{Ca}^{2+}$ channels; the remaining $55 \%$ are supported by a mixture of $\mathrm{N}$-type and $\mathrm{P} / \mathrm{Q}$-type $\mathrm{Ca}^{2+}$ channels (Reuter, 1995). One possible explanation for the partial effect of GFP-NC3 on STI antibody uptake is that GFP-NC3 causes only partial suppression of endogenous $\mathrm{N}$-type and $\mathrm{P} / \mathrm{Q}$-type $\mathrm{Ca}^{2+}$ channel function at synapses. An alternative explanation is that GFP-NC3 interferes with the synaptic function of N-type but not $\mathrm{P} / \mathrm{Q}$-type $\mathrm{Ca}^{2+}$ channels. To discriminate between these possibilities, we compared effects of GFP-NC3 on STI antibody uptake after preincubation of neuronal cultures with $5 \mu \mathrm{M}$ $\omega$-GVIA or $5 \mu \mathrm{M} \omega$-MVIIC conotoxins. The $\omega$-GVIA conotoxin is a selective inhibitor of $\mathrm{N}$-type $\mathrm{Ca}^{2+}$ channels (Boland et al., 1994), whereas $\omega$-MVIIC conotoxin blocks both N-type and P/Q-type $\mathrm{Ca}^{2+}$ channels (McDonough et al., 1996). The block of $\mathrm{N}$-type $\mathrm{Ca}^{2+}$ channels by $\omega$-MVIIC is rapidly reversible, with the time constant of $\sim 30 \mathrm{sec}$ (McDonough et al., 1996). In contrast, the block of P/Q-type channels by $\omega$-MVIIC and the block of $\mathrm{N}$-type $\mathrm{Ca}^{2+}$ channels by $\omega$-GVIA reverses on a time scale of hours (Boland et al., 1994; McDonough et al., 1996). We took 

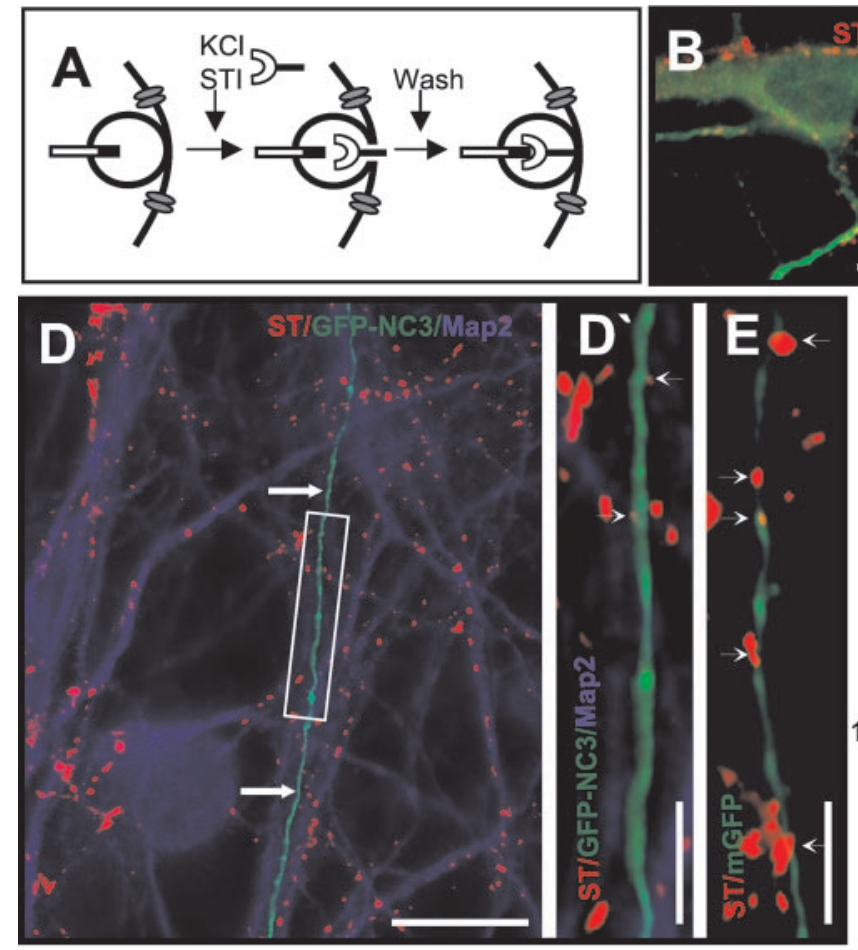
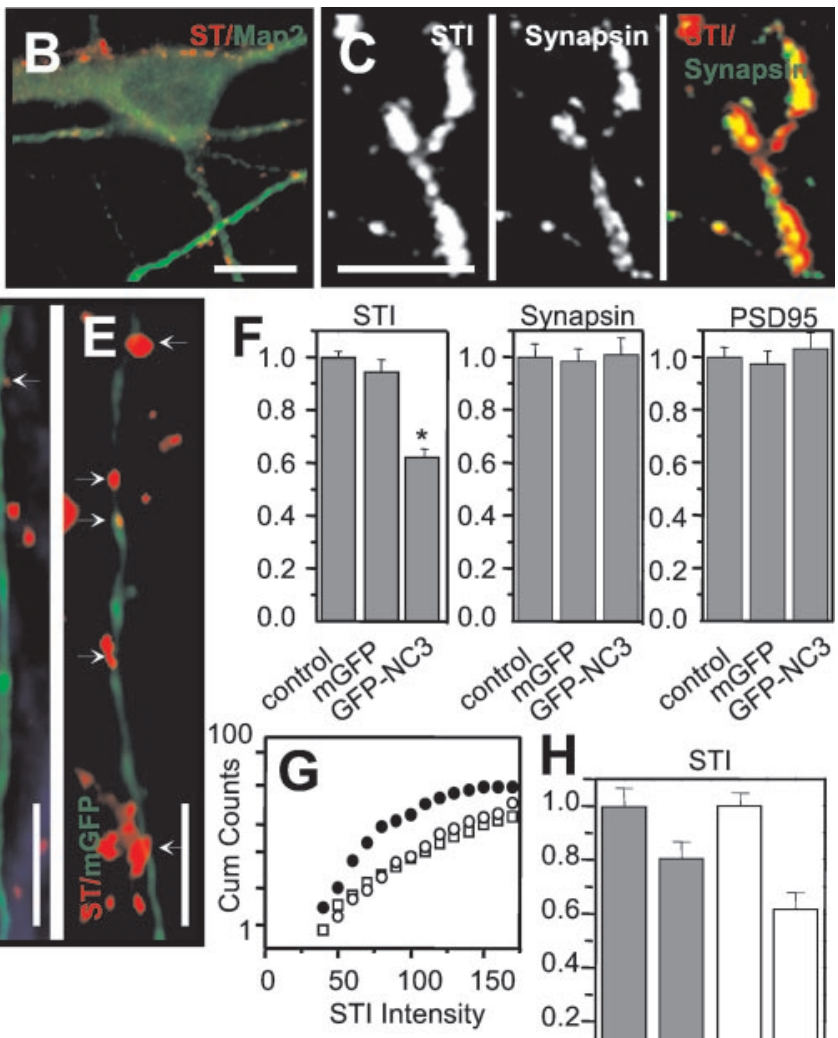

Synapsin

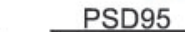

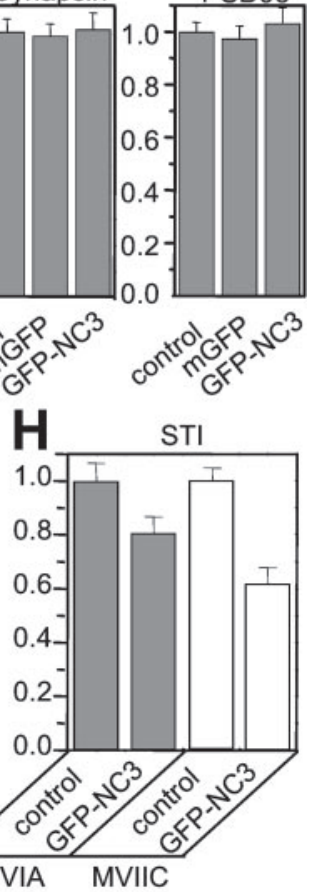

Figure 5. Dominant-negative effect of $\alpha_{1 \mathrm{~B}} \mathrm{C}$-terminal fragment on synaptic function. $A$, The experimental protocol for live labeling of active synapses with synaptotagmin luminal antibodies (STI) was adapted from Matteoli et al. (1992). The hippocampal neuronal cultures were preincubated with STI antibodies for $3 \mathrm{~min}$ in the presence of $45 \mathrm{~mm} \mathrm{KCl}$ and $2 \mathrm{~mm} \mathrm{Ca}^{2+}$. After stimulation, STI antibodies were washed out, and neurons were fixed, permeabilized, and stained with rhodamine-conjugated anti-mouse secondary antibody to visualize STI antibody localization. The intraluminal epitope of synaptotagmin is shown as a black box. B, Live labeling for STI (red) followed by fixation and labeling for MAP2 (green). Note that all STI-positive clusters are apposed to cell body and dendrites (MAP2-positive). Scale bar, $20 \mu \mathrm{m}$. C, Live staining for STI (left panel, red in merged image) followed by fixation and staining for synapsin (center panel, green on merged image) shows colocalization of STI clusters with presynaptic sites. On average, $93 \%$ of STI and synapsin clusters were colocalized $(n=200)$. Scale bar, $10 \mu \mathrm{m}$. $D$, Live staining for STI (red) of GFP-NC3 (green)-transfected neurons followed by fixation and staining for MAP2 (blue). Axons of transfected cells ( green, MAP2-negative) are indicated by large arrows. The boxed portion of the image is enlarged in the $D^{\prime}$ inset. Note that the intensity of individual STI clusters associated with axons of transfected neurons is reduced when compared with control clusters formed by GFP-NC3-negative axons. Small arrows in $D^{\prime}$ indicate synapses of transfected cells. Scale bars: $D, 20 \mu \mathrm{m} ; D^{\prime}$, $10 \mu \mathrm{m}$. E, Live staining for STI (red) of neurons expressing mGFP (green). Note that the intensity of individual STI clusters associated with axons of mGFP-transfected neurons is not affected. Small arrows in $E$ indicate synapses of transfected cells. Scale bar, $10 \mu \mathrm{m}$. $F$, Quantitative analysis of the intensity of individual clusters of STI (left panel), synapsin (center panel), and PSD-95 (right panel) associated with control (nontransfected) cells and cells transfected with mGFP or GFP-NC3 as indicated. For each transfection, the fluorescence intensity of individual STI, synapsin, and PSD-95 clusters was normalized to the average fluorescence intensity of corresponding clusters observed for control (nontransfected) cells in the same field. The normalized intensities are shown as mean $\pm \operatorname{SEM}(n=$ number of clusters analyzed). For STI plot: control, $n=309 ; \mathrm{mGFP}, n=55$; GFP-NC3, $n=$ $90\left({ }^{*} p<0.001\right.$ when GFP-NC3 is compared with control and mGFP). For synapsin and PSD-95, $n \geq 75$ for controls and $n \geq 25$ for mGFP and GFP-NC3. $G$, Cumulative distribution of intensities of individual STI clusters associated with axons of nontransfected neurons (control, $\square$ ) or axons of neurons expressing mGFP $(\bigcirc)$ and GFP-NC3 $(\bullet)$. $H$, Effect of GFP-NC3 expression on STI uptake by neurons preincubated with $5 \mu \mathrm{M} \omega$-GVIA or $5 \mu \mathrm{M}$ $\omega$-MVIIC ( $n \geq 25$ for each group).

advantage of these kinetic differences in the design of our experiments. Before exposure of hippocampal neuronal cultures to $\mathrm{KCl}$ and STI antibody, we removed the toxins and washed the cultures for 3-5 min in PBS. During the wash period, the block of N-type channels by $\omega$-MVIIC, but not the block of P/Q-type channels by $\omega$-MVIIC or the block of N-type channels by $\omega$-GVIA, was reversed. Thus, in our experiments $\mathrm{P} / \mathrm{Q}$-type $\mathrm{Ca}^{2+}$ channels were selectively blocked by $\omega$-MVIIC conotoxin during $\mathrm{KCl}$ stimulation and STI labeling. The latter conclusion was supported by our observation that the mixture of both $\omega$-GVIA and $\omega$-MVIIC conotoxins abolished STI clusters in our cultures (data not shown), whereas a large number of STI clusters were observed in the presence of $\omega$-GVIA or $\omega$-MVIIC conotoxins alone. When cultures were preincubated with either $\omega$-GVIA or $\omega$-MVIIC conotoxins, overexpression of GFP-NC3 caused a significant suppression of the average intensity of observed STI clusters when compared with nontransfected neurons (Fig. $5 H$ ). From these data, we concluded that GFP-NC3 has similar inhibitory effects on the synaptic function of either $\mathrm{N}$-type or $\mathrm{P} / \mathrm{Q}$-type $\mathrm{Ca}^{2+}$ channels, and that the synaptic function of endogenous $\mathrm{Ca}^{2+}$ 

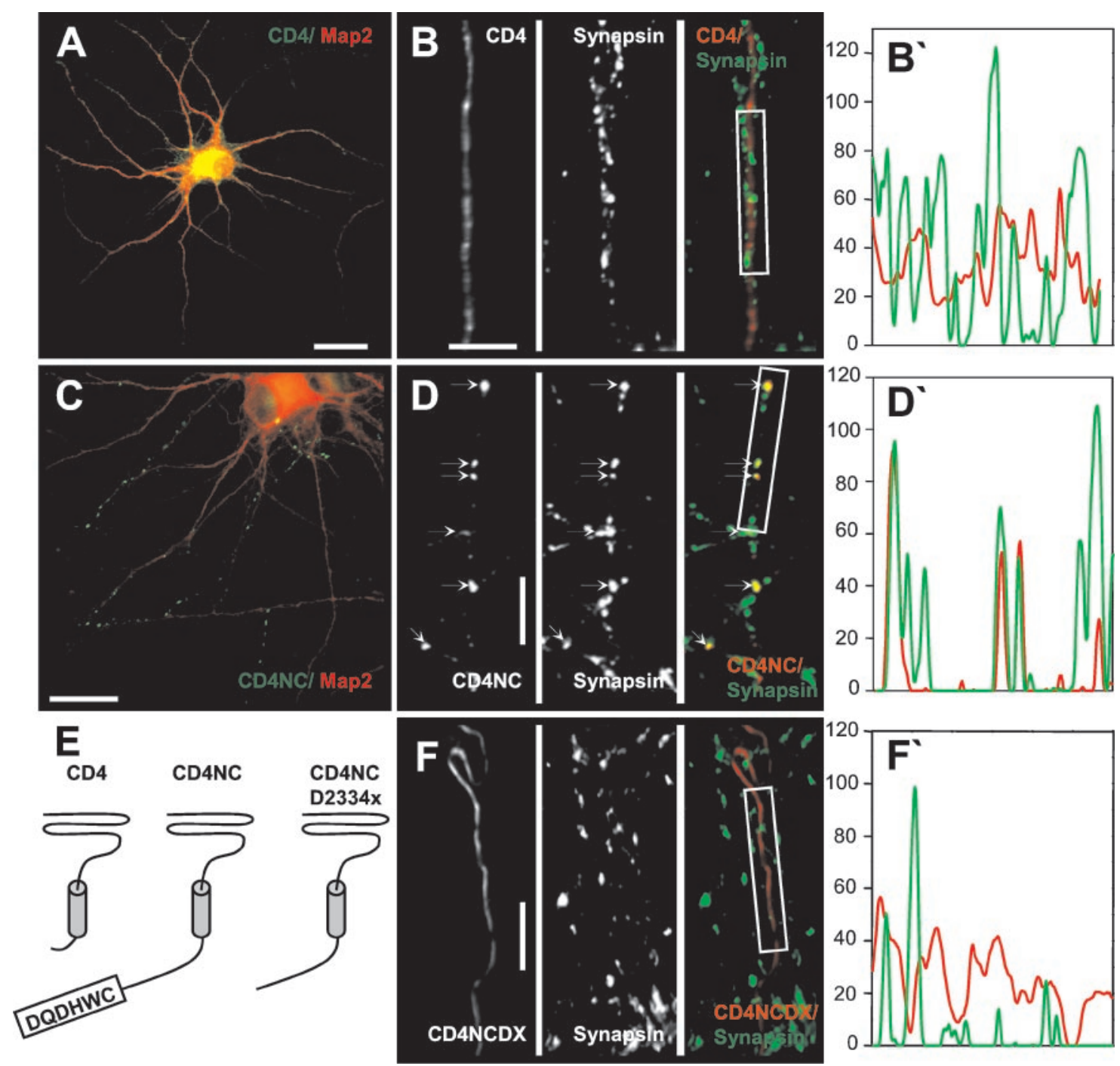

Figure 6. Synaptic targeting of CD4-NC construct. CD4, CD4-NC, and CD4-NC-D2334X chimeric constructs were transfected into high-density rat hippocampal neurons at 10-11 DIV, and their subcellular localization was visualized by immunostaining with CD4 or CD4-FITC antibodies 3-4 d after transfection. $A, C$, MAP2 (red) and CD4 (green) staining of high-density hippocampal neuronal cultures transfected with CD4 $(A)$ and CD4-NC $(C)$. Scale bars, $20 \mu \mathrm{m} . B, D, F, C D 4$ (left panel, red in merged image) and synapsin (center panel, green in merged image) localization in axons of neurons transfected with CD4 $(B)$, CD4-NC $(D)$, or CD4-NC-D2334X $(F)$. CD4 clusters are indicated by small arrows $(D)$. CD4-negative clusters of synapsin correspond to synaptic terminals of nontransfected neurons in the field of view. The fluorescence intensity profiles (CD4, red; synapsin, green) of the boxed regions in $B, D$, and $F$ are shown on $B^{\prime}, D^{\prime}$, and $F^{\prime}$, respectively. Scale bars, $10 \mu \mathrm{m}$. $E$, Topological models of CD4, CD4-NC, and CD4-NC-D2334X targeting constructs.

channels is only partially disrupted by GFP-NC3 overexpression in hippocampal neuronal cultures.

\section{Synaptic targeting of CD4- $\alpha_{1 \mathrm{~B}}-\mathrm{NC}$ chimeric constructs in hippocampal neurons}

In the previous sections, we established that the C-terminal region of the $\alpha_{1 \mathrm{~B}}$ subunit (amino acids 2177-2339) is necessary for synaptic clustering of $\mathrm{N}$-type $\mathrm{Ca}^{2+}$ channels in mature highdensity neuronal cultures. Are N-type $\mathrm{Ca}^{2+}$ channel $\mathrm{C}$ termini also sufficient for synaptic targeting? To answer this question, we generated a model chimeric construct, CD4-NC, composed of an extracellular human CD4 receptor ectodomain, a single human CD4 receptor transmembrane domain, and a short fragment of human $\alpha_{1 \mathrm{~B}}$ cytosolic tail (Fig. 6E, diagram). In the resulting CD4-NC construct, most of the $\alpha_{1 \mathrm{~B}}-\mathrm{NC1} \mathrm{C}$ terminus, including the proline-rich region, was removed from the sequence, leaving the short region in the beginning of the $\mathrm{C}$-tail and the most
C-terminal region containing the PDZ domain-binding consensus. To evaluate the role of the PDZ domain-binding motif, the control CD4-NC-D2334X construct, which lacked the last 6 aa, was also generated (Fig. 6E, diagram). The human truncated CD4 receptor construct (CD4) served as a negative control in these experiments.

The CD4, CD4-NC, and CD4-NC-D2334X constructs were transfected into mature high-density rat hippocampal neurons. Double labeling with CD4-FITC and MAP2 antibodies demonstrated that the expressed CD4 receptor was diffusely distributed in all processes of transfected cells (Fig. 6A). In contrast, the CD4-NC protein was clustered in axons (Fig. $6 C$ ). Double labeling with monoclonal CD4 and polyclonal synapsin antibodies revealed that CD4-NC clusters colocalize with synaptic sites (Fig. $\left.6 D, D^{\prime}\right)$. In contrast, diffuse distribution of CD4 immunoreactivity did not correlate with synapsin localization (Fig. $\left.6 B, B^{\prime}\right)$. The 
presence of the PDZ domain-binding motif appears to be essential for synaptic clustering of CD4-NC, because the CD4-NCD2334X construct was diff usely distributed and did not colocalize with synapsin (Fig. $6 F, F^{\prime}$ ). It is important to note that the CD4-NC and CD4-NC-D2334X constructs lack a proline-rich region (amino acids P2039-P2194) in their sequence, which probably accounts for the differences observed in HA- $\alpha_{1 \mathrm{~B}}-\mathrm{D} 2334 \mathrm{X}$ and CD4-NC-D2334X distribution (Figs. 3C, 6F). Indeed, a diffuse axonal distribution of the CD4-NC-D2334X construct (Fig. $6 F$ ) is similar to diffuse localization of the HA- $\alpha_{1 \mathrm{~B}}-\mathrm{PXXP}-\mathrm{A} /$ D2334X double mutant (Fig. 3D). It is interesting to note that the soluble GFP-NC3 construct was diffusely distributed in hippocampal neurons (Figs. $3 E, 5 D$ ), indicating that the presence of the transmembrane domain in the CD4-NC construct is essential for synaptic targeting. From experiments with the CD4-NC targeting constructs, we concluded that the C-terminal region of $\alpha_{1 \mathrm{~B}}$ is sufficient for targeting of the CD4 receptor to the presynaptic sites in mature high-density hippocampal neuronal cultures. In the absence of the proline-rich region, the synaptic targeting function of $\alpha_{1 \mathrm{~B}} \mathrm{C}$ termini is completely determined by the presence of the PDZ domain-binding motif.

The PDZ domain-binding motif is conserved between $\alpha_{1 \mathrm{~B}}$ and $\alpha_{1 \mathrm{~A}}$ pore-forming subunits (Maximov et al., 1999). Does the $\mathrm{C}$ terminal of the $\alpha_{1 \mathrm{~A}}$ subunit also act as synaptic targeting signal? To answer this question, we generated CD4-QC and CD4-QCD2501X constructs (see Materials and Methods), expressed these constructs in mature hippocampal neuronal cultures, and performed double labeling with monoclonal CD4 and polyclonal synapsin antibodies. Similar to the CD4-NC construct, we found that the CD4-QC construct was clustered at synaptic locations, whereas the CD4-QC-D2501X construct was diff usely distributed in axons (data not shown). Thus, the PDZ domain-binding consensus at $\mathrm{C}$ termini of $\alpha_{1 \mathrm{~A}}$ (P/Q-type $\mathrm{Ca}^{2+}$ channels) also functions as synaptic targeting signal.

\section{Potential role of Mint1 and CASK adaptor proteins in N-type $\mathrm{Ca}^{2+}$ channel targeting to synapse}

Our experiments (Figs. 3, 6) established the importance of PDZ and SH3 domain-binding motifs in $\alpha_{1 \mathrm{~B}} \mathrm{C}$ termini for N-type $\mathrm{Ca}^{2+}$ channel synaptic targeting in hippocampal neurons. In a previous paper (Maximov et al., 1999), we demonstrated that the same motifs specifically associate with the Mint1-PDZ1 and CASK-SH3 adaptor domains. To determine whether Mint1 and CASK can play a role in $\mathrm{N}$-type $\mathrm{Ca}^{2+}$ channel targeting in neurons, we expressed GFP-tagged Mint1 and CASK in mature high-density hippocampal neuronal cultures. GFP-Mint1 and GFP-CASK were present in both axonal (MAP2-negative) and somatodendritic (MAP2-positive) domains (Fig. 7A, $C$ ). In axons, GFP-Mint1 and GFP-CASK form distinct clusters (Fig. 7B,D). The observed clusters were juxtaposed to MAP2-positive processes (Fig. 7B,D) and precisely colocalized with synapsin clusters (data not shown). Thus, similar to recombinant N-type channels, recombinant Mint1 and CASK are clustered in presynaptic terminals of mature rat hippocampal neurons.

Do Mint1, CASK, and N-type $\mathrm{Ca}^{2+}$ channels cluster in the same locations? To answer this question, we coexpressed recombinant HA-tagged $\mathrm{N}$-type $\mathrm{Ca}^{2+}$ channels with GFP-Mint1 or GFP-CASK. We found that GFP-Mint1, GFP-CASK, and HA$\alpha_{1 \mathrm{~B}}$ were coclustered at mature synapses formed by the same cell (Fig. 7E,F). Is it possible that N-type channels clustered at synaptic sites bind GFP-Mint1 and GFP-CASK, leading to their concentration at synapses? To address this question, we coex-

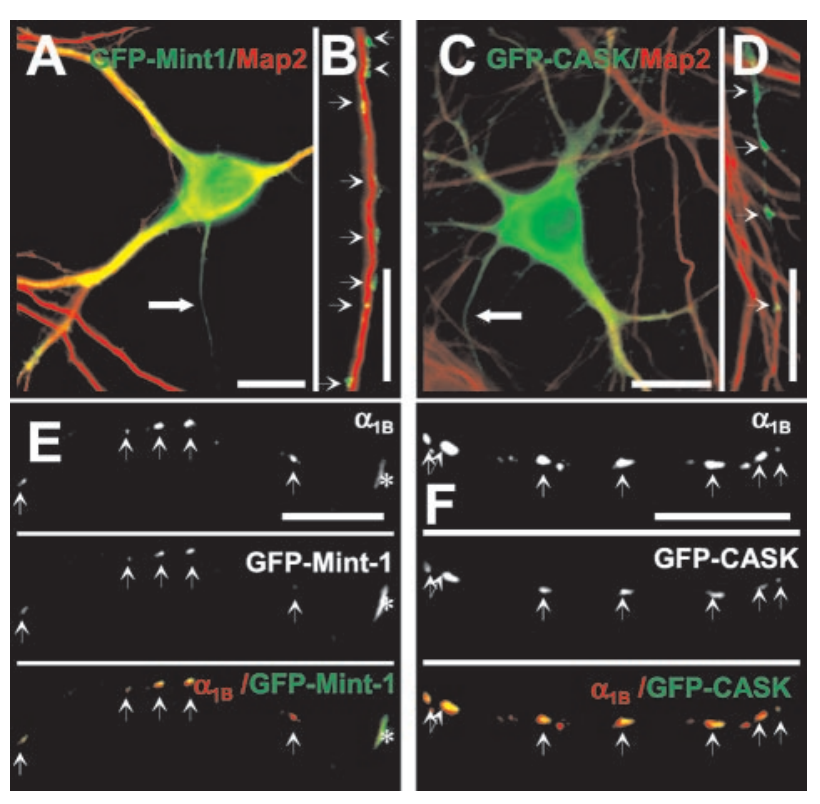

Figure 7. Colocalization of recombinant Mint1 and CASK with N-type channels in mature hippocampal neurons. $A-D$, High-density hippocampal neuronal cultures transfected with GFP-Mint1 $(A, B)$ and GFP-CASK $(B, D)$ plasmids at 9 DIV. At 3-5 d after transfection, the localization of GFP-Mint1 or GFP-CASK ( green) and endogenous MAP2 (red) was determined. The somatodendritic domain $(A, C)$ and distal axonal segment $(B, D)$ of transfected cells are shown. Proximal axonal segments are indicated by arrows $(A, C)$. Presynaptic clusters of GFP-Mint1 $(B)$ and GFP-CASK $(D)$ associated with axons of transfected neurons apposed to dendrites (MAP2-positive) are indicated by small arrows. Scale bars, 20 $\mu \mathrm{m}$. $E, F$, High-density mature hippocampal neurons cotransfected with HA- $\alpha_{1 \mathrm{~B}} / \alpha_{2} \delta / \beta_{3}$ and GFP-Mint1 $(E)$ or GFP-CASK $(F)$ at 9 DIV. At $4 \mathrm{~d}$ after transfection, the axonal distribution of HA- $\alpha_{1 \mathrm{~B}}$ (top panel, red in merged image) and GFP-Mint1 (E, center panel, green in merged image) or GFP-CASK $(F$, center panel, green in merged image $)$ was determined. Synaptic clusters of HA- $\alpha_{1 \mathrm{~B}}$, GFP-Mint1, and GFP-CASK are indicated by small arrows. Axonal growth cones are indicated by asterisks in E. Scale bars, $20 \mu \mathrm{m}$.

pressed GFP-Mint1 and GFP-CASK with HA-NC3 construct (HA tag fused to the $\alpha_{1 \mathrm{~B}}$ fragment between amino acids 20212339). In interpretation of these experiments, we assumed that the HA-NC3 construct is expressed at levels far above the levels of endogenous N-type $\mathrm{Ca}^{2+}$ channels. If binding of Mint1 and/or CASK to $\alpha_{1 \mathrm{~B}} \mathrm{C}$ termini is required for their synaptic clustering, then the soluble HA-NC3 construct is expected to have a dominant negative effect on their synaptic targeting. However, we did not observe any changes in the subcellular distribution of GFPMint1 and GFP-CASK in the presence of HA-NC3 (data not shown). Thus, we concluded that Mint1 and CASK are likely to be targeted to synaptic sites independently of their association with $\mathrm{N}$-type $\mathrm{Ca}^{2+}$ channels.

\section{DISCUSSION}

Targeting of $\mathrm{N}$-type $\mathrm{Ca}^{2+}$ channels to synaptic locations in rat hippocampal neuronal cultures was investigated in this study. The main conclusions of our paper are: (1) that polarized distribution of $\mathrm{N}$-type $\mathrm{Ca}^{2+}$ channels in neurons depends on the formation of synapses; (2) that the C-terminal 163 aa (amino acids 2177-2339) of the long splice variant of the $\mathrm{N}$-type pore-forming subunit $\alpha_{1 \mathrm{~B}}$ $\left(\alpha_{1 \mathrm{~B}-1}, \mathrm{Ca}_{\mathrm{V}} 2.2 \mathrm{a}\right)$ is necessary and sufficient for synaptic targeting of N-type $\mathrm{Ca}^{2+}$ channels; (3) that PDZ and SH3 domain-binding motifs in the $\alpha_{1 \mathrm{~B}} \mathrm{C}$ termini constitute synergistic synaptic targeting signals; (4) that somatodendritic and axonal/synaptic isoforms 
of N-type channels are generated via alternative splicing of $\alpha_{1 \mathrm{~B}} \mathrm{C}$ termini; and (5) that it is likely that Mint1 and CASK adaptor proteins play a role in $\mathrm{N}$-type $\mathrm{Ca}^{2+}$ channel synaptic targeting.

\section{Structural determinants of $\mathrm{N}$-type channel synaptic targeting in hippocampal neurons}

Polarized sorting of dendritic proteins in neurons appears to be guided by intrinsic sorting signals (Craig and Banker, 1994; Burack et al., 2000; Silverman et al., 2001). The mechanisms involved in targeting of axonal proteins appear to be more diverse. Neuronal sorting of axonal protein neuron-glia cell adhesion molecule (NgCAM) (Burack et al., 2000), the synaptic vesicle components synapsin and synaptophysin (Fletcher et al., 1991), and the presynaptic metabotropic glutamate receptor 7 (mGluR7) (Stowell and Craig, 1999; Boudin et al., 2000) has been investigated previously. It was concluded that the axonal selection of $\mathrm{NgCAM}$ happens at the step downstream of vesicular transport, either as a result of selective membrane fusion or selective retention. The axonal sorting of mGluR7 happens by a nonexclusion mechanism with the receptors present in both dendrites and axons (Stowell and Craig, 1999). Targeting of synaptic vesicle proteins appears to proceed as two-step process: initial axonal targeting based on intrinsic sorting signals followed by clustering at presynaptic sites that depend on cell contacts (Fletcher et al., 1991; Craig and Banker, 1994). In our experiments with recombinant N-type $\mathrm{Ca}^{2+}$ channels expressed in immature or low-density hippocampal cultures, we observed uniform distribution of channels in axonal and somatodendritic compartments (Figs. 1, 2D). Similar uniform distribution of native N-type channels in immature hippocampal neurons was reported using immunostaining (Bahls et al., 1998) and functional (Pravettoni et al., 2000) methods. In contrast, in mature, high-density cultures recombinant N-type $\mathrm{Ca}^{2+}$ channels (Fig. 2A-C,H,I) and mGluR7 (Boudin et al., 2000) were clustered in synapses and primarily excluded from soma and dendrites. Contact-dependent clustering of endogenous $\mathrm{N}$-type $\mathrm{Ca}^{2+}$ channels (Bahls et al., 1998) and synapsin (Fletcher et al., 1991) was described previously. From these results it appears that the targeting of axonal ( $\mathrm{NgCAM})$ proteins is guided by intrinsic sorting signals (Burack et al., 2000), but polarized distribution of presynaptic proteins (mGluR7 and N-type $\mathrm{Ca}^{2+}$ channels) depends on cell-to-cell contact and synapse formation.

Human (Williams et al., 1992), chicken (Lu and Dunlap, 1999), and rat (this study) $\alpha_{1 \mathrm{~B}}$ subunits undergo alternative splicing in the $\mathrm{C}$-terminal region. Our results suggest that in mature highdensity cultures, the long $\alpha_{1 \mathrm{~B}}-\mathrm{NC} 1$ splice variant $\left(\alpha_{1 \mathrm{~B}-1}, \mathrm{Ca}_{\mathrm{V}} 2.2 \mathrm{a}\right)$ is the axonal/presynaptic isoform (Fig. $2 A-C, H, I$ ), and the short $\alpha_{1 \mathrm{~B}}-\mathrm{NC} 2$ splice variant $\left(\alpha_{1 \mathrm{~B}-2}, \mathrm{Ca}_{\mathrm{V}} 2.2 \mathrm{~b}\right)$ is the somatodendritic isoform (Fig. 4B). Similar to the $\alpha_{1 \mathrm{~B}}$ subunit, the P/Q-type channel pore-forming subunit $\alpha_{1 \mathrm{~A}}\left(\mathrm{Ca}_{\mathrm{V}} 2.1\right)$ is alternatively spliced at the $\mathrm{C}$ termini (Zhuchenko et al., 1997). The long C-terminal splice variant of the $\alpha_{1 \mathrm{~A}}$ subunit $\left(\alpha_{1 \mathrm{~A}-1}, \mathrm{Ca}_{\mathrm{V}} 2.1 \mathrm{a}\right)$, but not the short splice variants, contains a similar PDZ domainbinding motif (Maximov et al., 1999). We suggest that the N-type and the $\mathrm{P} / \mathrm{Q}$-type $\mathrm{Ca}^{2+}$ channels are targeted to synapses via interactions with a similar or identical set of adaptor proteins. We also suggest that an alternative splicing of the $\alpha_{1 \mathrm{~B}}$ and $\alpha_{1 \mathrm{~A}}$ subunit $\mathrm{C}$ termini provides a potential regulatory mechanism of $\mathrm{N}$-type and $\mathrm{P} / \mathrm{Q}$-type $\mathrm{Ca}^{2+}$ channel sorting. In the case of $\mathrm{P} / \mathrm{Q}$-type $\mathrm{Ca}^{2+}$ channels, association of $\alpha_{1 \mathrm{~A}} \mathrm{C}$ terminal with an auxiliary $\beta_{4}$ subunit (Walker et al., 1998) may play an additional role in synaptic targeting (Wittemann et al., 2000). It is also possible that truncation of SH3, PDZ, and $\beta_{4}$ binding motifs in the $\alpha_{1 \mathrm{~A}}$ subunit
(Fletcher et al., 1996) may lead to mistargeting of P/Q-type $\mathrm{Ca}^{2+}$ channels in the leaner mice, resulting in severe neurological phenotype. A recent report suggested the importance of alternative splicing in the $\alpha_{1 \mathrm{~A}}$ subunit II/III loop region for P/Q-type $\mathrm{Ca}^{2+}$ channel sorting between axonal and somatodendritic compartments of GABAergic cortical neurons (Timmermann et al., 2002). Novel II/III splice variants of human $\alpha_{1 \mathrm{~B}}$ subunit that lack the soluble SNARE-binding synprint site were identified recently (Kaneko et al., 2002). At the moment it is not clear whether alternative splicing of the $\alpha_{1 \mathrm{~B}}$ and $\alpha_{1 \mathrm{~A}}$ II/III loop and C-terminal regions are independent or correlated events, and future studies will be needed to answer this question. However, these data suggest that the alternative splicing-dependent sorting of $\mathrm{Ca}^{2+}$ channels in neurons may be a general phenomenon.

\section{The role of modular adaptor proteins in synaptic targeting of $\mathbf{N}$-type channels}

PDZ domain-containing proteins play an important role in protein sorting in polarized cells (Yeaman et al., 1999) and in

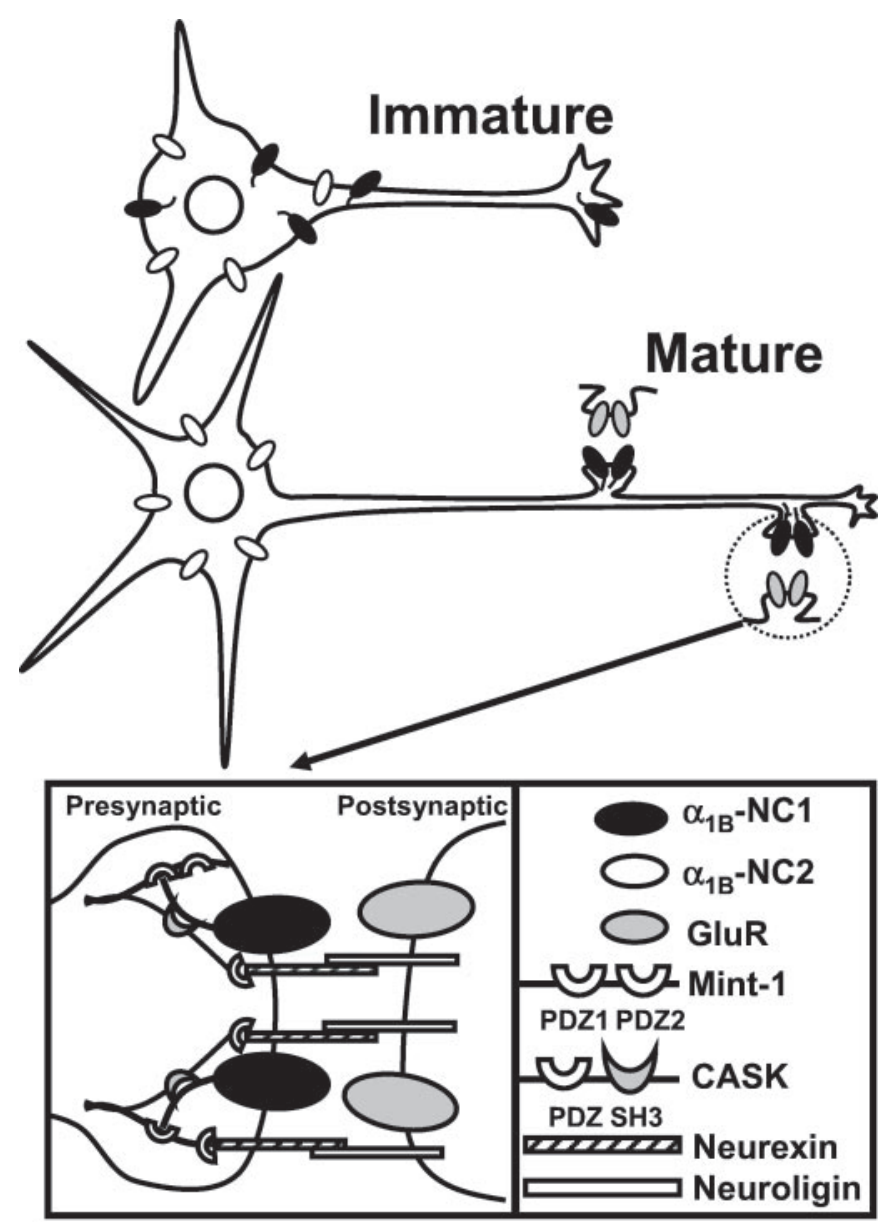

Figure 8. Model of N-type $\mathrm{Ca}^{2+}$ channel synaptic targeting in neurons. N-type $\mathrm{Ca}^{2+}$ channels formed by $\alpha_{1 \mathrm{~B}}-\mathrm{NC} 1\left(\alpha_{1 \mathrm{~B}-1}, \mathrm{Ca}_{\mathrm{V}} 2.2 \mathrm{a}\right)$ (black) pore-forming subunit are distributed diffusely and uniformly in immature neurons, whereas $\alpha_{1 \mathrm{~B}}-\mathrm{NC} 2\left(\alpha_{1 \mathrm{~B}-2}, \mathrm{Ca}_{\mathrm{v}} 2.2 \mathrm{~b}\right)$ (white) is localized in the somatodendritic domain (top). After synaptogenesis (bottom), the $\alpha_{1 \mathrm{~B}}-\mathrm{NC} 1$ subunits are clustered at synapses, and the $\alpha_{1 \mathrm{~B}}-\mathrm{NC} 2$ subunits remain restricted to soma and dendrites. The association of $\alpha_{1 \mathrm{~B}} \mathrm{NC1} \mathrm{C}$ terminal with Mint1-PDZ1 and CASK-SH3 domains (Maximov et al., 1999) (inset) links synaptic N-type channels to neurexin-neuroligin neuronal adhesion complex (Irie et al., 1997; Nguyen and Sudhof, 1997; Butz et al., 1998; Song et al., 1999) and is likely to play a role in the synaptic clustering of the channels. 
synaptic organization (Fanning and Anderson, 1996; Kornau et al., 1997; Craven and Bredt, 1998). The PKC-interacting protein-1 (PICK1)-PDZ domain-binding motif in the mGluR7 $\mathrm{C}$ terminal is essential for presynaptic clustering of mGluR7 (Boudin et al., 2000). In the case of N-type $\mathrm{Ca}^{2+}$ channels, the synaptic targeting function of the PDZ domain-binding motif is synergistic with the function of the upstream $\mathrm{SH} 3$ domainbinding motif (Fig. 3C-F), most likely because the corresponding PDZ and SH3 domain-containing adaptor proteins form a complex with each other. Removal of both motifs or expression of a dominant-negative GFP-NC3 construct containing both motifs prevents clustering of recombinant $\mathrm{N}$-type $\mathrm{Ca}^{2+}$ channel (Fig. 3). The same GFP-NC3 construct exerts a dominantnegative effect on synaptic function (Fig. 5). Thus, in cases of both mGluR7 receptors and $\mathrm{N}$-type $\mathrm{Ca}^{2+}$ channels, Cterminal-mediated interactions with PDZ domain adaptor proteins are involved in synaptic clustering. Axonal sorting of $\mathrm{NgCAM}$ is not likely to use a similar mechanism, because addition of GFP to the $\mathrm{NgCAM} \mathrm{C}$ terminal did not affect its targeting to axons (Burack et al., 2000).

What adaptor proteins are involved in N-type channel targeting? We reported previously (Maximov et al., 1999) that there was specific association of the $\alpha_{1 \mathrm{~B}} \mathrm{C}$-terminal region with the first PDZ domain in the neuronal adaptor protein Mint1 and with the $\mathrm{SH} 3$ domain of the adaptor protein CASK. More recently, we have shown that $\alpha_{1 \mathrm{~B}} \mathrm{C}$ termini also bind to INADL-5, PAR6, and MUPP1-9 PDZ domains (Bezprozvanny and Maximov, 2001). The proline-rich region of the $\alpha_{1 \mathrm{~B}} \mathrm{C}$ terminal has been implicated recently in interactions with the $\mathrm{SH} 3$ domain of RBP (Hibino et al., 2002). Thus, a number of adaptor proteins may play a role in $\mathrm{N}$-type $\mathrm{Ca}^{2+}$ channel synaptic targeting. At present, Mint1 and CASK are the best candidates for an important role in $\mathrm{N}$-type $\mathrm{Ca}^{2+}$ channel synaptic targeting. Indeed, in Caenorhabditis elegans, the tripartite complex of the Mint1 homolog lin-10 with adaptor proteins lin-2 (CASK homolog) and lin-7 (veli homolog) mediates targeting of the LET-23 receptor in polarized epithelia (Rongo et al., 1998). Mint1/CASK/veli forms a homologous complex in the brain (Borg et al., 1998, 1999; Butz et al., 1998). Direct association of Mint1 and CASK may explain the synergism in the synaptic targeting function of the PDZ and SH3 domain-binding motifs in the $\alpha_{1 \mathrm{~B}} \mathrm{C}$ termini (Fig. 3). When expressed in neurons, GFP-Mint1 and GFP-CASK clustered at synapses (Fig. 7B,D) and colocalized in presynaptic locations with recombinant $\mathrm{N}$-type $\mathrm{Ca}^{2+}$ channels (Fig. 7E,F). Recent analysis by electron microscopy reported the presence of endogenous Mint1 in presynaptic terminals (Okamoto et al., 2000). A potential role for Mint1 in targeting of the NMDA receptor to postsynaptic density has also been suggested (Setou et al., 2000), and the Mint1-binding partner CASK has been found on both sides of the synaptic cleft (Hsueh et al., 1998). Thus, it is possible that the Mint1/CASK/ veli complex or a similar complex is involved in targeting of ion channels and receptors on both sides of the synapse. A similar conclusion has been drawn regarding the PICK1 protein, implicated in mGluR7 clustering at presynaptic terminals (Boudin et al., 2000), which is found at both sides of the synapse (Torres et al., 1998; Xia et al., 1999). Future experiments, which will likely use the knock-out mice approach, should help to dissect the role played by Mint1, CASK, and other adaptor proteins in $\mathrm{Ca}^{2+}$ channel targeting to the axonal compartment and recruitment to synapses.

\section{The model of $\mathrm{N}$-type channel synaptic targeting in hippocampal neurons}

The main conclusions of our study can be summarized in the form of a model (Fig. 8). We suggest that before synaptogenesis, $\mathrm{N}$-type $\mathrm{Ca}^{2+}$ channels containing $\alpha_{1 \mathrm{~B}}-\mathrm{NC} 1\left(\alpha_{1 \mathrm{~B}-1}, \mathrm{Ca}_{\mathrm{V}} 2.2 \mathrm{a}\right)$ subunit are diffusely and uniformly distributed in both axonal and somatodendritic compartments of immature neurons, whereas $\alpha_{1 \mathrm{~B}}-\mathrm{NC} 2\left(\alpha_{1 \mathrm{~B}-2}, \mathrm{Ca}_{\mathrm{V}} 2.2 \mathrm{~b}\right)$ subunits are only present in neuronal soma and dendrites (Fig. 8, top). After synapse formation, the channels formed by $\alpha_{1 \mathrm{~B}}-\mathrm{NC} 1$ subunit are concentrated at axons and clustered at synapses, and the channels formed by $\alpha_{1 \mathrm{~B}} \mathrm{NC2}$ splice variant are restricted to soma and dendrites (Fig. 8, bottom). Analogous redistribution of native $\mathrm{N}$-type $\mathrm{Ca}^{2+}$ channels during synaptogenesis in rat hippocampal neuronal cultures has been suggested previously on the basis of immunolocalization (Bahls et al., 1998) and functional (Pravettoni et al., 2000) experiments. Clustering of $\mathrm{N}$-type $\mathrm{Ca}^{2+}$ channels in synaptic locations appears to be mediated by extrinsic regulatory cues, which most likely involve neuronal adhesion molecules. The Mint1/CASK/ veli complex in the brain is associated with the neurexin-neuroligin synaptic junctional complex (Irie et al., 1997; Nguyen and Sudhof, 1997; Butz et al., 1998; Song et al., 1999; Biederer and Sudhof, 2000). Recent results suggest a primary role of neurexinneuroligin association in the induction of presynaptic differentiation (Rao et al., 2000; Scheiffele et al., 2000). The association of $\alpha_{1 \mathrm{~B}}$-NC1 C termini with the Mint1/CASK/veli-neurexin/neuroligin complex (Maximov et al., 1999) (Fig. 8, inset) provides a possible molecular mechanism for $\mathrm{N}$-type $\mathrm{Ca}^{2+}$ channel synaptic targeting during synaptogenesis.

\section{REFERENCES}

Bahls FH, Lartius R, Trudeau LE, Doyle RT, Fang Y, Witcher D, Campbell K, Haydon PG (1998) Contact-dependent regulation of N-type calcium channel subunits during synaptogenesis. J Neurobiol 35:198-208

Bezprozvanny I, Maximov A (2001) Classification of PDZ domains. FEBS Lett 509:457-462.

Bezprozvanny I, Scheller RH, Tsien RW (1995) Functional impact of syntaxin on gating of N-type and Q-type calcium channels. Nature 378:623-626.

Bichet D, Cornet V, Geib S, Carlier E, Volsen S, Hoshi T, Mori Y, De Waard M (2000) The I-II loop of the $\mathrm{Ca}^{2+}$ channel $\alpha$ 1 subunit contains an endoplasmic reticulum retention signal antagonized by the $\beta$ subunit. Neuron 25:177-190.

Biederer T, Sudhof TC (2000) Mints as adaptors. Direct binding to neurexins and recruitment of munc18. J Biol Chem 275:39803-39806.

Boland LM, Morrill JA, Bean BP (1994) $\omega$-Conotoxin block of N-type calcium channels in frog and rat sympathetic neurons. J Neurosci 14:5011-5027.

Borg JP, Straight SW, Kaech SM, de Taddeo-Borg M, Kroon DE, Karnak D, Turner RS, Kim SK, Margolis B (1998) Identification of an evolutionarily conserved heterotrimeric protein complex involved in protein targeting. J Biol Chem 273:31633-31636.

Borg JP, Lopez-Figueroa MO, de Taddeo-Borg M, Kroon DE, Turner RS, Watson SJ, Margolis B (1999) Molecular analysis of the X11mLin-2/CASK complex in brain. J Neurosci 19:1307-1316.

Boudin H, Doan A, Xia J, Shigemoto R, Huganir R, Worley P, Craig AM (2000) Presynaptic clustering of mGluR7a requires the PICK1 PDZ domain binding site. Neuron 28:485-497.

Burack MA, Silverman MA, Banker G (2000) The role of selective transport in neuronal protein sorting. Neuron 26:465-472.

Butz S, Okamoto M, Sudhof TC (1998) A tripartite protein complex with the potential to couple synaptic vesicle exocytosis to cell adhesion in brain. Cell 94:773-782.

Craig AM, Banker G (1994) Neuronal polarity. Annu Rev Neurosci 17:267-310

Craven SE, Bredt DS (1998) PDZ proteins organize synaptic signaling pathways. Cell 93:495-498.

Crawley JN, Gerfen CR, McKay R, Rogawski MA, Sibley DR, Skolnick P, eds (1997) Current protocols in neuroscience. New York: Wiley.

Dalgarno DC, Botfield MC, Rickles RJ (1997) SH3 domains and drug design: ligands, structure, and biological function. Biopolymers 43:383-400 
Dubel SJ, Starr TV, Hell J, Ahlijanian MK, Enyeart JJ, Catterall WA, Snutch TP (1992) Molecular cloning of the $\alpha-1$ subunit of an $\omega$-conotoxin-sensitive calcium channel. Proc Natl Acad Sci USA 89:5058-5062.

Dunlap K, Luebke JI, Turner TJ (1995) Exocytotic $\mathrm{Ca}^{2+}$ channels in mammalian central neurons. Trends Neurosci 18:89-98.

Ellinor PT, Zhang J-F, Horne WA, Tsien RW (1994) Structural determinants of the blockage of N-type calcium channels by a peptide neurotoxin. Nature 372:272-275.

Ertel EA, Campbell KP, Harpold MM, Hofmann F, Mori Y, Perez-Reyes E, Schwartz A, Snutch TP, Tanabe T, Birnbaumer L, Tsien RW, Catterall WA (2000) Nomenclature of voltage-gated calcium channels. Neuron 25:533-535.

Fanning AS, Anderson JM (1996) Protein-protein interactions: PDZ domain networks. Curr Biol 6:1385-1388.

Fletcher CF, Lutz CM, O’Sullivan TN, Shaughnessy Jr JD, Hawkes R, Frankel WN, Copeland NG, Jenkins NA (1996) Absence epilepsy in tottering mutant mice is associated with calcium channel defects. Cell 87:607-617.

Fletcher TL, Banker GA (1989) The establishment of polarity by hippocampal neurons: the relationship between the stage of a cell's development in situ and its subsequent development in culture. Dev Biol 136:446-454.

Fletcher TL, Cameron P, De Camilli P, Banker G (1991) The distribution of synapsin I and synaptophysin in hippocampal neurons developing in culture. J Neurosci 11:1617-1626.

Goslin K, Asmussen H, Banker G (1998) Rat hippocampal neurons in low density culture. In: Culturing nerve cells (Banker G, Goslin K, eds), pp 339-370. Cambridge, MA: MIT.

Hata Y, Butz S, Sudhof TC (1996) CASK: a novel dlg/PSD95 homolog with an N-terminal calmodulin-dependent protein kinase domain identified by interaction with neurexins. J Neurosci 16:2488-2494.

Hell JW, Appleyard SM, Yokoyama CT, Warner C, Catterall WA (1994) Differential phosphorylation of two size forms of the N-type calcium channel $\alpha 1$ subunit which have different $\mathrm{COOH}$ termini. J Biol Chem 269:7390-7396.

Hibino H, Pironkova R, Onwumere O, Vologodskaia M, Hudspeth AJ, Lesage F (2002) RIM binding proteins (RBPs) couple Rab3interacting molecules (RIMs) to voltage-gated $\mathrm{Ca}^{2+}$ channels. Neuron 34:411-423.

Higgins D, Burack M, Lein P, Banker G (1997) Mechanisms of neuronal polarity. Curr Opin Neurobiol 7:599-604.

Hsueh YP, Yang FC, Kharazia V, Naisbitt S, Cohen AR, Weinberg RJ, Sheng M (1998) Direct interaction of CASK/LIN-2 and syndecan heparan sulfate proteoglycan and their overlapping distribution in neuronal synapses. J Cell Biol 142:139-151.

Hullin R, Singer-Lahat D, Freichel M, Biel M, Dascal N, Hofmann F, Flockerzi V (1992) Calcium channel $\beta$ subunit heterogeneity: functional expression of cloned cDNA from heart, aorta, and brain. EMBO J 11:885-890.

Irie M, Hata Y, Takeuchi M, Ichtchenko K, Toyoda A, Hirao K, Takai Y, Rosahl TW, Sudhof TC (1997) Binding of neuroligins to PSD-95. Science 277:1511-1515

Jones DH, Matus AI (1974) Isolation of synaptic plasma membrane from brain by combined flotation-sedimentation density gradient centrifugation. Biochim Biophys Acta 356:276-287.

Kaneko S, Cooper CB, Nishioka N, Yamasaki H, Suzuki A, Jarvis SE, Akaike A, Satoh M, Zamponi GW (2002) Identification and characterization of novel human $\mathrm{Ca}_{\mathrm{v}} 2.2(\alpha 1 \mathrm{~B})$ calcium channel variants lacking the synaptic protein interaction site. J Neurosci 22:82-92.

Kornau HC, Seeburg PH, Kennedy MB (1997) Interaction of ion channels and receptors with PDZ domain proteins. Curr Opin Neurobiol 7:368-373.

Llinas R, Steinberg IZ, Walton K (1981) Relationship between presynaptic calcium current and postsynaptic potential in squid giant synapse. Biophys J 33:323-351.

Lu Q, Dunlap K (1999) Cloning and functional expression of novel N-type $\mathrm{Ca}^{2+}$ channel variants. J Biol Chem 274:34566-34575.

Matteoli M, Takei K, Perin MS, Sudhof TC, De Camilli P (1992) Exoendocytotic recycling of synaptic vesicles in developing processes of cultured hippocampal neurons. J Cell Biol 117:849-861.

Maximov A, Sudhof TC, Bezprozvanny I (1999) Association of neuronal calcium channels with modular adaptor proteins. J Biol Chem 274:24453-24456.

Mayer BJ (2001) SH3 domains: complexity in moderation. J Cell Sci 114:1253-1263.

McDonough SI, Swartz KJ, Mintz IM, Boland LM, Bean BP (1996) Inhibition of calcium channels in rat central and peripheral neurons by $\omega$-conotoxin M VIIC. J Neurosci 16:2612-2623.

Mikami A, Imoto K, Tanabe T, Niidome T, Mori Y, Takeshima H, Narumiya S, Numa S (1989) Primary structure and functional expression of the cardiac dihydropyridine-sensitive calcium channel. Nature 340:230-233

Mori Y, Friedrich T, Kim M-S, Mikami A, Nakai J, Ruth P, Bosse E,
Hofmann F, Flockerzi V, Furuichi T, Mikoshiba K, Imoto K, Tanabe T, Numa S (1991) Primary structure and functional expression from complementary DNA of a brain calcium channel. Nature 350:398-402.

Moriyoshi K, Richards L, Akazawa C, O'Leary DD, Nakanishi S (1996) Labeling neural cells using adenoviral gene transfer of membranetargeted GFP. Neuron 16:255-260.

Nguyen T, Sudhof TC (1997) Binding properties of neuroligin 1 and neurexin $1 \beta$ reveal function as heterophilic cell adhesion molecules. J Biol Chem 272:26032-26039.

Okamoto M, Sudhof TC (1997) Mints, Munc18-interacting proteins in synaptic vesicle exocytosis. J Biol Chem 272:31459-31464.

Okamoto M, Matsuyama T, Sugita M (2000) Ultrastructural localization of mint 1 at synapses in mouse hippocampus. Eur $\mathrm{J}$ Neurosci 12:3067-3072.

Pravettoni E, Bacci A, Coco S, Forbicini P, Matteoli M, Verderio C (2000) Different localizations and functions of L-type and N-type calcium channels during development of hippocampal neurons. Dev Biol 227:581-594.

Qin N, Platano D, Olcese R, Stefani E, Birnbaumer L (1997) Direct interaction of $\mathrm{g} \beta \gamma$ with a C-terminal $\mathrm{g} \beta \gamma$-binding domain of the $\mathrm{Ca}^{2+}$ channel $\alpha 1$ subunit is responsible for channel inhibition by $\mathrm{G}$ proteincoupled receptors. Proc Natl Acad Sci USA 94:8866-8871.

Rao A, Harms KJ, Craig AM (2000) Neuroligation: building synapses around the neurexin-neuroligin link. Nat Neurosci 3:747-749.

Reuter H (1995) Measurements of exocytosis from single presynaptic nerve terminals reveal heterogeneous inhibition by $\mathrm{Ca}^{2+}$-channel blockers. Neuron 14:773-779.

Rongo C, Whitfield CW, Rodal A, Kim SK, Kaplan JM (1998) LIN-10 is a shared component of the polarized protein localization pathways in neurons and epithelia. Cell 94:751-759.

Scheiffele P, Fan J, Choih J, Fetter R, Serafini T (2000) Neuroligin expressed in nonneuronal cells triggers presynaptic development in contacting axons. Cell 101:657-669.

Setou M, Nakagawa T, Seog DH, Hirokawa N (2000) Kinesin superfamily motor protein KIF17 and mLin-10 in NMDA receptor-containing vesicle transport. Science 288:1796-1802.

Silverman MA, Kaech S, Jareb M, Burack MA, Vogt L, Sonderegger P, Banker G (2001) Sorting and directed transport of membrane proteins during development of hippocampal neurons in culture. Proc Natl Acad Sci USA 98:7051-7057.

Song JY, Ichtchenko K, Sudhof TC, Brose N (1999) Neuroligin 1 is a postsynaptic cell-adhesion molecule of excitatory synapses. Proc Natl Acad Sci USA 96:1100-1105.

Stowell JN, Craig AM (1999) Axon/dendrite targeting of metabotropic glutamate receptors by their cytoplasmic carboxy-terminal domains. Neuron 22:525-536.

Takahashi T, Momiyama A (1993) Different types of calcium channels mediate central synaptic transmission. Nature 366:156-158.

Timmermann DB, Westenbroek RE, Schousboe A, Catterall WA (2002) Distribution of high-voltage-activated calcium channels in cultured $\gamma$-aminobutyric acidergic neurons from mouse cerebral cortex. J Neurosci Res 67:48-61.

Torres R, Firestein BL, Dong H, Staudinger J, Olson EN, Huganir RL, Bredt DS, Gale NW, Yancopoulos GD (1998) PDZ proteins bind, cluster, and synaptically colocalize with Eph receptors and their ephrin ligands. Neuron 21:1453-1463.

Tsien RW, Ellinor PT, Horne WA (1991) Molecular diversity of voltagedependent Ca channels. Trends Pharm Sci 12:349-354.

Walker D, Bichet D, Campbell KP, De Waard M (1998) A $\beta 4$ isoformspecific interaction site in the carboxyl-terminal region of the voltagedependent $\mathrm{Ca}^{2+}$ channel $\alpha 1 \mathrm{~A}$ subunit. J Biol Chem 273:2361-2367.

Wheeler DB, Randall A, Tsien RW (1994) Roles of N-type and Q-type $\mathrm{Ca}$ channels in supporting hippocampal synaptic transmission. Science 264:107-111.

Williams ME, Brust PF, Feldman DH, Patthi S, Simerson S, Maroufi A, McCue AF, Velicelebi G, Ellis SB, Harpold MM (1992) Structure and functional expression of an $\omega$-conotoxin-sensitive human N-type calcium channel. Science 257:389-395.

Winckler B, Mellman I (1999) Neuronal polarity: controlling the sorting and diffusion of membrane components. Neuron 23:637-640.

Wittemann S, Mark M, Rettig J, Herlitze S (2000) Synaptic localization and presynaptic function of calcium channel $\beta 4$-subunits in cultured hippocampal neurons. J Biol Chem 275:37807-37814.

Xia J, Zhang X, Staudinger J, Huganir RL (1999) Clustering of AMPA receptors by the synaptic PDZ domain-containing protein PICK1. Neuron 22:179-187.

Yeaman C, Grindstaff KK, Hansen MD, Nelson WJ (1999) Cell polarity: versatile scaffolds keep things in place. Curr Biol 9:R515-R517.

Zhuchenko O, Bailey J, Bonnen P, Ashizawa T, Stockton DW, Amos C, Dobyns WB, Subramony SH, Zoghbi HY, Lee CC (1997) Autosomal dominant cerebellar ataxia (SCA6) associated with small polyglutamine expansions in the $\alpha 1 \mathrm{~A}$-voltage-dependent calcium channel. Nat Genet 15:62-69. 